\title{
d4PDF: large-ensemble and high-resolution climate simulations for global warming risk assessment
}

\author{
Masayoshi Ishii ${ }^{1,2^{*}}$ and Nobuhito Mori ${ }^{3}$
}

\begin{abstract}
A large-ensemble climate simulation database, which is known as the database for policy decision-making for future climate changes (d4PDF), was designed for climate change risk assessments. Since the completion of the first set of climate simulations in 2015, the database has been growing continuously. It contains the results of ensemble simulations conducted over a total of thousands years respectively for past and future climates using high-resolution global (60 km horizontal mesh) and regional (20 km mesh) atmospheric models. Several sets of future climate simulations are available, in which global mean surface air temperatures are forced to be higher by $4 \mathrm{~K}, 2 \mathrm{~K}$, and $1.5 \mathrm{~K}$ relative to preindustrial levels. Nonwarming past climate simulations are incorporated in d4PDF along with the past climate simulations. The total data volume is approximately 2 petabytes. The atmospheric models satisfactorily simulate the past climate in terms of climatology, natural variations, and extreme events such as heavy precipitation and tropical cyclones. In addition, data users can obtain statistically significant changes in mean states or weather and climate extremes of interest between the past and future climates via a simple arithmetic computation without any statistical assumptions. The database is helpful in understanding future changes in climate states and in attributing past climate events to global warming. Impact assessment studies for climate changes have concurrently been performed in various research areas such as natural hazard, hydrology, civil engineering, agriculture, health, and insurance. The database has now become essential for promoting climate and risk assessment studies and for devising climate adaptation policies. Moreover, it has helped in establishing an interdisciplinary research community on global warming across Japan.
\end{abstract}

Keywords: Global warming, d4PDF, Ensemble climate simulation, Atmospheric model, Dynamical downscaling, Detection and attribution, Impact assessment, Climate change adaptation, Natural hazard, Storm surge

\section{Introduction}

Following the series of the Intergovernmental Panel on Climate Change (IPCC) Fifth Assessment Report published in 2013 and 2014, the Paris Agreement was adopted in December 2015. Globally, governments started designing adaptation measures for future increases in global

\footnotetext{
*Correspondence: maish@mri-jma.go.jp

'Department of Atmosphere, Ocean and Earth System Modeling Research,

Meteorological Research Institute, 1-1 Nagamine, Tsukuba, Ibaraki 305-0052, Japan

${ }^{2}$ Climate and Environment Research Promotion, Japan Meteorological

Business Support Center, Kanda-Nishikicho, Chiyoda-ku, Tokyo 101-0054, Japan

Full list of author information is available at the end of the article
}

warming. To devise consistent adaptation measures for flood control, agriculture, city planning, and risk prevention in human lives and social infrastructures, it is essential for governmental agencies and political decisionmakers to adopt a future scenario commonly used across socio-economic and environmental fields between adjacent geographical regions. At present, people are particularly concerned for the severe weather and extreme hazards that are caused by global warming. To address this concern, the climate information should be detailed in space and time.

\section{Springer Open}

(0) The Author(s). 2020 Open Access This article is licensed under a Creative Commons Attribution 4.0 International License, which permits use, sharing, adaptation, distribution and reproduction in any medium or format, as long as you give appropriate credit to the original author(s) and the source, provide a link to the Creative Commons licence, and indicate if changes were made. The images or other third party material in this article are included in the article's Creative Commons licence, unless indicated otherwise in a credit line to the material. If material is not included in the article's Creative Commons licence and your intended use is not permitted by statutory regulation or exceeds the permitted use, you will need to obtain permission directly from the copyright holder. To view a copy of this licence, visit http://creativecommons.org/licenses/by/4.0/. 


\subsection{A brief history}

In 1989, Meteorological Research Institute (MRI) started researches on global warming. They first conducted climate simulations by an atmospheric model coupled to a slab ocean model (Noda and Tokioka 1989), and the result was provided to the first IPCC assessment report. Since then, MRI has contributed to all IPCC assessment reports published so far and has developed atmosphere-ocean coupled models (Tokioka et al. 1995; Yukimoto et al. 2001) and earth system models (Adachi et al. 2013; Yukimoto et al. 2019) in parallel. From 2002 to 2016, enhanced global warming studies were conducted under three Japanese research programs supported by the Japanese ministry, MEXT, in which the University of Tokyo, JAMSTEC, MRI, NIES, Kyoto University, and other institutes participated. These programs developed climate models (Hasumi and Emori 2004; Nozawa et al. 2007; Watanabe et al. 2010; Tatebe et al. 2019), a high-resolution coupled atmosphere and ocean model (Sakamoto et al. 2012), and ambitious earth system models (Kawamiya et al. 2005; Watanabe et al. 2011; Hajima et al. 2020) that were used for future climate projections. Under these programs, climate studies were also performed on the global and regional scales, along with interdisciplinary climate impact assessment studies (Nakakita et al. 2018). Further, event attribution studies requiring large-ensemble model simulations (e.g., Watanabe et al. 2013) were conducted by the Program for Risk Information on Climate Change (SOUSEI, from FY2012 to FY2016).

During the SOUSEI program, there were strong demands for the contribution to society utilizing their research results obtained during the programs. Concurrently, it was pointed out that existing model outputs for future climate states were insufficient for devising suitable adaptation measures in Japan based on impact projections and assessments (Mori et al. 2016; Takemi et al. 2016). In the programs, time-slice projection (Kitoh et al. 2016), in which high-resolution AGCMs are integrated for past and future periods of several tens of years, had been used to obtain impact projections and assessment of climate change. However, the number of events sampled from the available climate simulations was insufficient to estimate extreme natural hazards in particular regions. Furthermore, reliable probabilistic information on the extremes of $1 / 20$ to $1 / 200$-year return periods, for instance, was required for hardware countermeasure design for extreme natural hazards. Here, an $N$-year extreme refers to an exceedance probability of once per $N$ years. When the sampling size is small, the uncertainty in estimated occurrence frequency of the extremes is large. Therefore, increasing the climate simulation period was highly desirable for the impact projection and assessment, and for adaptation to future extreme hazards.
Therefore, they developed future scenarios at several warming levels in the twenty-first century by performing numerous members of climate simulations using highresolution global and regional atmospheric models forced by observed and future sea surface temperatures projected by CMIP5 participating models. The simulation experiments were designed such that past climate signals and future changes in extreme events such as heat wave, heavy rainfall, and tropical cyclones as well as in climate extremes are detectable with high statistical confidence, based on the climate simulations as total of thousands years. The database containing the simulation outputs was named d4PDF. Further details of d4PDF will be presented below.

The future climate simulations of d4PDF were first conducted in 2015 (Mizuta et al. 2017). In the simulations, the global surface air temperatures (SATs) are set to climatologically constant at $+4 \mathrm{~K}$ relative to preindustrial levels, corresponding to the end of the twenty-first century in the RCP8.5 scenario experiments of the CMIP5 participating models. In December 2015 when the first d4PDF was released, the Paris Agreement was adopted, in which efforts to maintain the temperature below +2 $\mathrm{K}$ was promoted with global cooperation. To meet this goal, the Japanese cabinet decided to plan policies for climate change adaptation with an outline report entitled "National Plan for Adaptation to the Impacts of Climate Change in November 2015." Under this background, a climate science and social implementation program of MEXT called SI-CAT (from FY2015 to FY2019) decided to conduct further future climate simulations at a warming level of $+2 \mathrm{~K}$ as a subset of d4PDF (Fujita et al. 2019). Adaptation or countermeasures against global warming are not only governmental issues but also social problems. Since August 2018, d4PDF has become open to both commercial and noncommercial applications.

A new research program for Integrated Research Program for Advancing Climate Models (TOUGOU, from FY2017 to FY2021) has started in 2017. As one of research themes in TOUGOU, an update of d4PDF is currently planned and designed.

\subsection{Aims of d4PDF}

The main purpose of the database is to become a standard for use in devising policies at Japanese ministries and agencies, as well as in global warming and impact assessment studies. Governments and stakeholders are particularly concerned with future severe atmospheric extremes and their uncertainties. To realize this, d4PDF is constituted by the high-resolution and large-ensemble climate simulations, aiming at re-examining previous results on climate changes including past and future extreme events and at drawing highly reliable conclusions in both climate and assessment studies. Climate researchers focus 
on physical backgrounds and mechanisms of climate changes with d4PDF. The large-ensemble simulations also enable them to perform factor analyses of climate variations such as detection and attribution and event attribution on a near real-time basis. Such research activities would contribute to the progress of operational climate monitoring, for instance, done by World Meteorological Organization (2019) and related operational centers. Researchers on impact and risk assessments conduct their assessment models using the d4PDF. Bias corrections of the model-generated atmospheric variables are often required to stabilize the performances in the assessment results. Information engineering approaches are sometimes effective to extract statistical characteristics of atmospheric events from the large database. To handle the large database, brand-new techniques on data service must be introduced. All these research activities form an interdisciplinary community on global warming research (Fig. 1). This community hopefully functions for realization of effective countermeasure against global warming and for progress in science, engineering, agriculture, etc. In addition, all results of the community contribute to improvement in a future version of climate simulation and prediction databases.

Internationally, several similar databases exist. In 2009, the UK produced the global warming prediction database in collaboration with national agencies (UKCP09; Jenkins et al. 2009), in order to assess future climate risks. This is an epoch-making database since probability distribution functions (PDFs) of future climate states can be drawn from the database. The database was updated in 2018 (UKCP18; Met Office 2018). Both UKCP18 and $\mathrm{d} 4 \mathrm{PDF}$ enable probabilistic evaluations of occurrence of extreme events, although the former treats a wider range of uncertainties in future climates by using a coupled model rather than an atmospheric model, more CMIP5 model states, and physics parameter ensemble. The spatial resolution of the UKCP18 regional climate model is $12 \mathrm{~km}$. In addition, UKCP18 includes perspectives of sea level rise diagnostically estimated. Another database called ClimEx (Leduc et al. 2019) has been produced as a large-ensemble regional forecast database for North American and European regions by using the Canadian regional climate model of $12 \mathrm{~km}$ resolution, dynamically downscaled from 50-member simulations of a single global climate model. The Max Planck Institute Grand Ensemble (MPI-GE; Maher et al. 2019) is an extension of CMIP5 historical and four RCP scenario experiments by a single low-resolution earth system model. In MPI-GE, the sets of 100-member simulations for each experiment provide robust estimates of forced response separated with internal variability. An international research project called CORDEX is a part of CMIP5 (and ongoing CMIP6 as well), and the project focuses on regional-scale global warming projections, adopting a multi-model ensemble approach (Giorgi et al. 2009).

\section{Review}

Now we review the use of d4PDF in climate and assessment studies on future climate changes. More than 70 papers related to d4PDF have been published since 2015, and all of these are presented in this review. The purpose of this review is to summarize the present d4PDF studies and to obtain perspectives of future climate simulation databases. First, atmospheric models and various climate simulations in d4PDF are described, and then past and future climate simulations are evaluated focusing on atmospheric phenomena on global and regional scales. Second, we introduce how d4PDF has been applied to impact assessment studies and social implementation. These are the planned goals of the database, that is, to provide high-resolution and large-ensemble data required for climate studies and risk assessments for various sectors in human society and the earth environment. Throughout this review, it is stressed that the high-resolution and large-ensemble climate simulations are effective for detecting signals of atmospheric extreme events and for practical applications to assessments of future climate risks. Data users in a wide range of research fields have raised new problems in the database. The future perspective on the database will be discussed in the final section. Figure 1 shows a schematic view of this review.

\subsection{Variants of climate simulation ... (1)}

Table 1 lists various climate simulations at different global warming levels, which constitute d4PDF. Global and regional atmospheric climate models of $60 \mathrm{~km}$ and $20 \mathrm{~km}$ meshes, respectively, are used for past and future climate simulations. The $60 \mathrm{~km}$ mesh resolution is approximately twice as high as the majority of CMIP5-participating models. The global model is the MRI atmospheric general circulation model version 3.2 (MRI-AGCM3.2; Mizuta et al. 2012) of a low-resolution setup, and the regional model is the nonhydrostatic regional climate model (NHRCM; Sasaki et al. 2011; Murata et al. 2013) covering Japanese Islands, the Korean Peninsula, and a part of the Asian continent. Spatiotemporally detailed simulation outputs were produced by dynamical downscaling with NHRCM using lateral boundary conditions given by MRI-AGCM3.2. These models are the same as the operational models formerly used at the Japan Meteorological Agency (JMA), although the physics schemes of the models were replaced by those suitable for climate simulations. The ensemble sizes of the experiments were more than 50, and a pair of both global and regional simulations was available in each subset.

All simulations listed in Table 1 were conducted by integrating the models forced by prescribed sea surface 


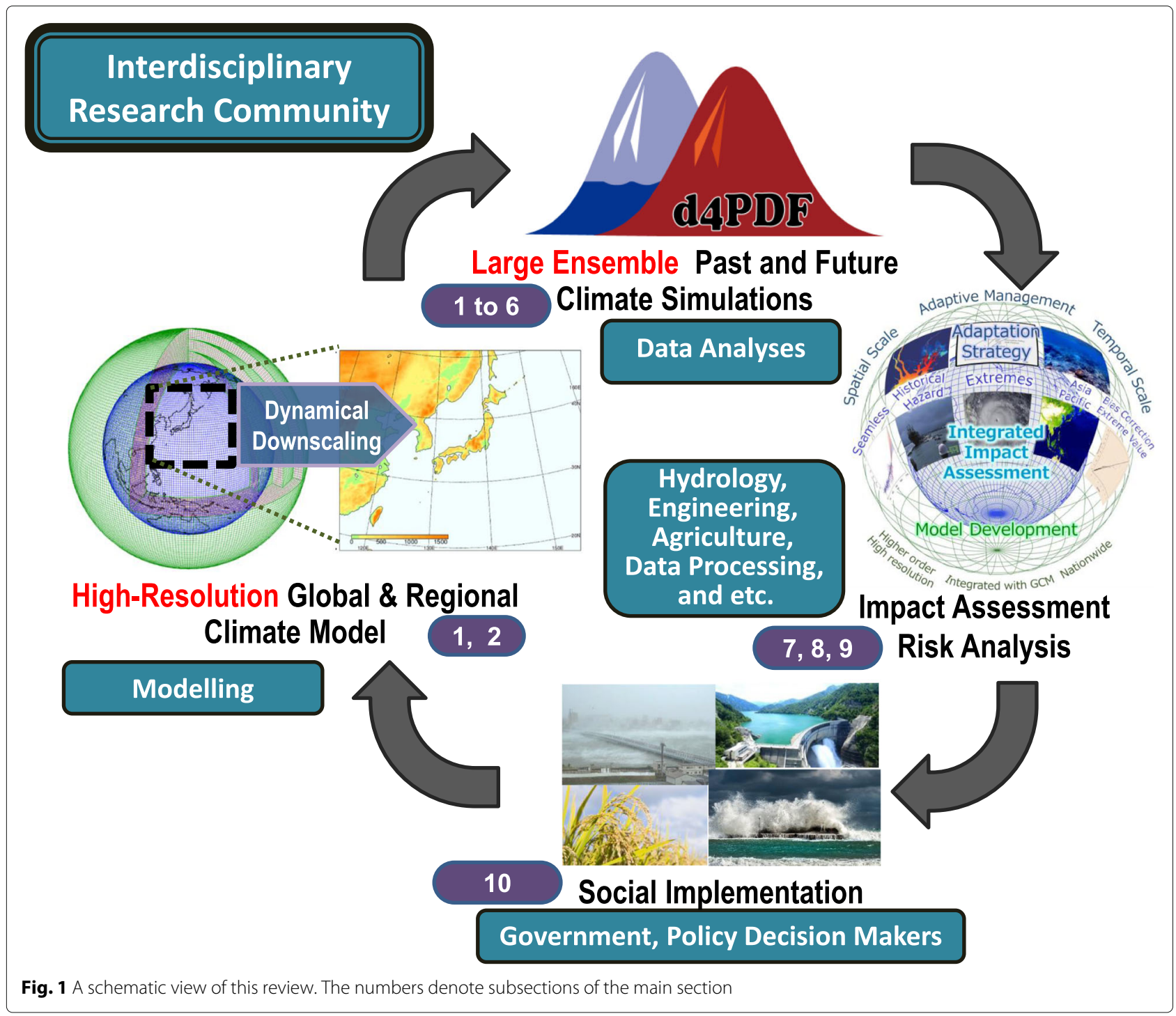

temperature (SST), sea ice concentration (SIC), and sea ice thickness (SIT). The greenhouse gas concentrations of CMIP5 (Taylor et al. 2012) were fed into the models. In the past climate simulation, observed SSTs, SIC, and SIT were used, where the SSTs and SIC are of COBE-
SST2 (Hirahara et al. 2014). Time-varying SIT is constructed and given as SIT monthly climatology (Bourke and Garrett 1987) multiplied by the observed SIC. Future simulations were performed assuming climatologically constant warming conditions of $+1.5 \mathrm{~K}$ (Nosaka et al.

Table 1 Subsets of climate simulation experiments in d4PDF under different climate conditions. $\Delta T$ in the forth column means differences in past and future climatologies of SST and SIC computed from CMIP5 RCP8.5 experiments by six climate models (CCSM4, GFDL-CM3, HadGEM2-AO, MIROC5, MPI-ESM-MR, and MRI-CGCM3). Two numbers in brackets following $\Delta$ T indicate the year range for RCP8.5 SST trend used in the future climate simulation. The baseline of nonwarming SSTs is the climatology for the period from 1900 to 1919

\begin{tabular}{|c|c|c|c|c|}
\hline Experiment & Ensemble members & Integration years/period & Boundary conditions & References \\
\hline Past & 100 & From 1951 onward & $\begin{array}{l}\text { Observed SSTs and SIC } \\
\text { (Hirahara et al. 2014) }\end{array}$ & Mizuta et al. (2017) \\
\hline Nonwarming & 100 & From 1951 onward & Detrended observed SSTs and SIC $: \delta_{\mathrm{T}}$ & Mizuta et al. (2017), Kawase et al. (2019) \\
\hline$+1.5 \mathrm{~K}$ future & 54 & 29 years $^{*} 1$ & $\Delta_{\mathrm{T}}(2020-2039)+\delta_{\mathrm{T}}$ & Nosaka et al. (2020) \\
\hline$+2 \mathrm{~K}$ future & 54 & 60 years & $\Delta_{\boldsymbol{T}}(2030-2049)+\delta_{\mathbf{T}}$ & Fujita et al. (2019) \\
\hline$+4 \mathrm{~K}$ future & 90 & 60 years & $\Delta_{\mathrm{T}}(2080-2099)+\delta_{\mathrm{T}}$ & Mizuta et al. (2017) \\
\hline
\end{tabular}

*1:the global model was integrated for 32 years 
2020), +2 K (Fujita et al. 2019), and +4 K (Mizuta et al. 2017), relative to preindustrial levels. Future SSTs used in these simulations were detrended observations added to the monthly SST trends of CMIP5 RCP8.5 experiments done by six different climate models : CCSM4 (Gent et al. 2011), GFDL-CM3 (Delworth et al. 2006; Donner et al. 2011), HadGen2-AO (Collins et al. 2011; Martin et al. 2011), MIROC5 (Watanabe et al. 2010), MPI-ESM-MR (Gioegetta et al. 2013), and MRI-CGCM3 (Yukimoto et al. 2011; Yukimoto et al. 2012), as shown in Fig. 2 and Table 2. The individual SST trends were rescaled by multiplying by a factor (Fujita et al. 2019; Mizuta et al. 2017; Nosaka et al. 2020; Shiogama et al. 2010) that forces MRIAGCM3.2 to simulate the global mean SATs equivalent to each warming level. Future SIC varies consistently with SSTs at geographical locations, which is determined by using quadratic relationships between SST and SIC as used in Hirahara et al. (2014). Coefficients of the quadratic equations were determined separately for each CMIP5 model so that climatological hemispheric sea ice areas are the same as those of multi-model ensemble mean SIC of the six CMIP5 models. Why the multi-model mean was used here is because the uncertainties of CMIP5 future SIC are quite large. The future SIT was given similarly to the case of the past SIT. Future changes in particular atmospheric variables are given by differences between the past and future climate simulations. This is sometimes referred to as a time-slice experiment (Kitoh et al. 2016).

In d4PDF, two sources of uncertainties are taken into account. One is the uncertainties in the CMIP5 scenario experiments accounted for by the future trends of the six CMIP5 models (Table 2). The other is those in internal (natural) variability induced by different initial and lower boundary conditions. The latter is perturbations of SST, SIC, and SIT which are represented as continuous fluctuations in space and time based on the uncertainty information of COBE-SST2. Although the magnitudes of the uncertainty vary in space and time depending on observation distributions, the magnitudes of the uncertainty are set constant in time. The SIC perturbations are made, being consistent with those of SST by using the quadratic relationship mentioned above, and SIT perturbations are computed as SIC perturbations multiplied by the SIT climatology. Merits in using SST, SIC, and SIT perturbations are to consider observational uncertainties in climate simulations and to optimize SST-force climate simulations. Or these are closely equivalent to using different SST and SIC analyses other than COBE-SST2. The global atmospheric model was integrated from several different initial conditions with the perturbed oceanic boundary conditions for 1 year before starting the main simulation runs. In the $+4 \mathrm{~K}$ experiment, the 90 ensemble members were constituted of combinations of the six SST trends and the 15 sets of oceanic perturbations, and the 6 trends times 9 perturbations for the $1.5 \mathrm{~K}$ and $+2 \mathrm{~K}$ experiments.

The global model simulations provide lateral boundary conditions for dynamical downscaling climate simulations in East Asia (Mizuta et al. 2017). A spectral nudging method is used for consistency between the global and regional large-scale climate states and for stabilization of the NHRCM integration (Murata et al. 2013; Sasaki et al. 2011), as adopted in other regional climate models (Giorgi 2019). The oceanic boundary conditions are the same as in the global model. An error in SIC used by NHRCM was reported by Nosaka et al. (2020), that is, no sea ice in the Okhotsk Sea given for all NHRCM simulations. The error

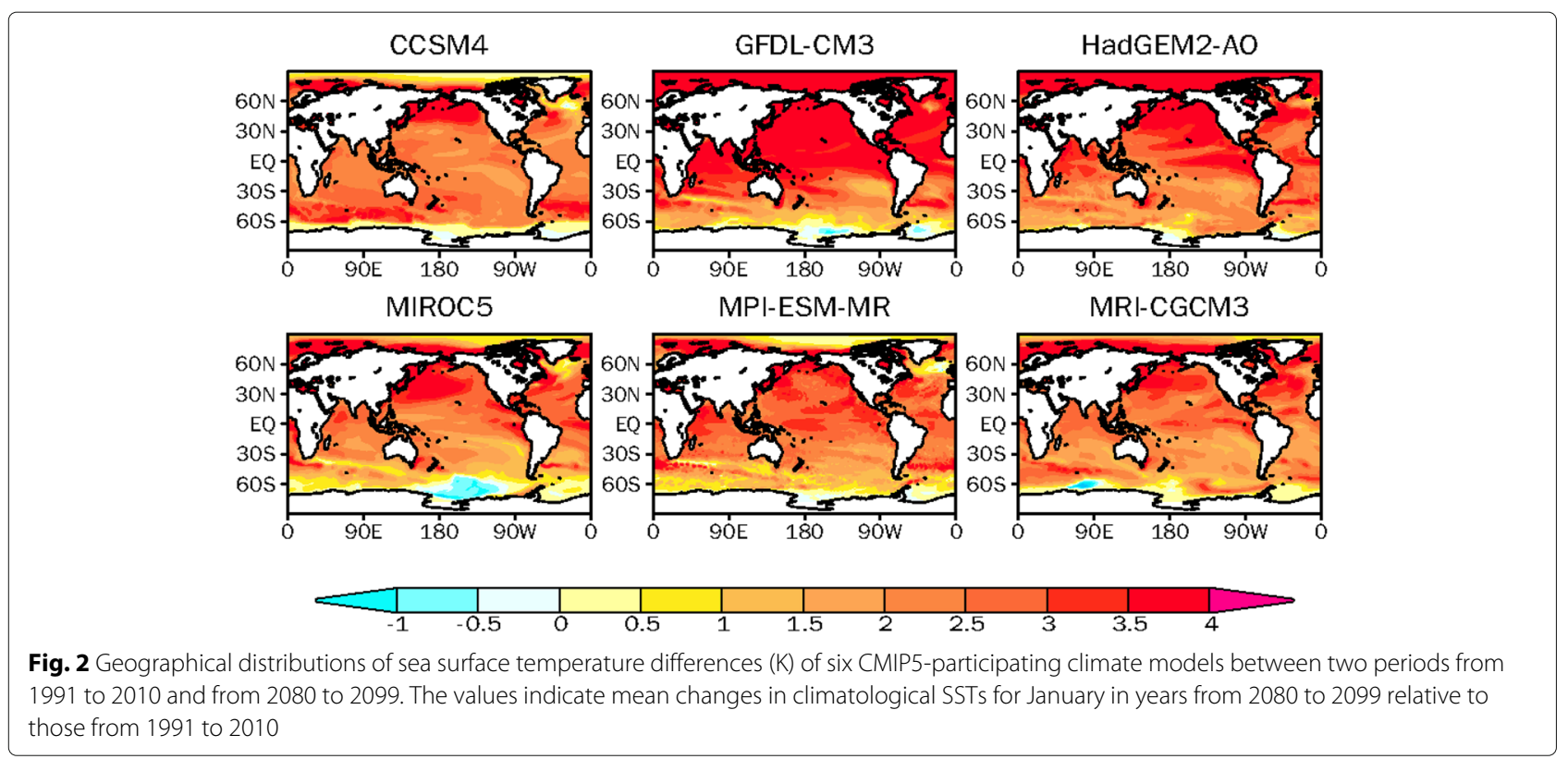


Table 2 List of CMIP5 models whose future climate projections are used in d4PDF. Please refer to Appendix 9.A of the IPCC Fifth Assessment Report (the Working Group I) for further details

\begin{tabular}{|c|c|c|c|}
\hline Acronym & Resolution (horizontal resol., vertical lev.s) & Center/institute, country & Refereces \\
\hline \multirow[t]{2}{*}{ CCSM } & AGCM: $0.9^{\circ} \times 1.25^{\circ}, 27$ & \multirow[t]{2}{*}{ National Centre for Atmospheric Research, USA } & \multirow[t]{2}{*}{ Gent et al. (2011) } \\
\hline & OGCM: nominal $1^{\circ}, 60$ & & \\
\hline \multirow[t]{2}{*}{ GFDL-CM3 } & AGCM: $\sim 200 \mathrm{~km}, 48$ & \multirow[t]{2}{*}{ Geophysical Fluid Dynamics Laboratory, USA } & Delworth et al. (2006) \\
\hline & OGCM: $1^{\circ}, 50$ & & Donner et al. (2011) \\
\hline \multirow[t]{2}{*}{ HadGEM2-AO } & AGCM: $1.875^{\circ} \times 1.25^{\circ}, 60$ & \multirow[t]{2}{*}{ National Institute of Meteorological Research, Korea } & Collins et al. (2011) \\
\hline & OGCM: $1.875^{\circ} \times 1.25^{\circ}$ & & Martin et al. (2011) \\
\hline \multirow[t]{2}{*}{ MIROC5 } & AGCM: $1.41^{\circ} \times 1.41^{\circ}, 40$ & \multirow[t]{2}{*}{ Univ. Tokyo and JAMTEC, Japan } & \multirow[t]{2}{*}{ Watanabe et al. (2010) } \\
\hline & OGCM: $1.4^{\circ} \times 0.5-1.4^{\circ}, 50$ & & \\
\hline \multirow[t]{2}{*}{ MPI-ESM-MR } & AGCM: approx. $1.8^{\circ}, 95$ & \multirow[t]{2}{*}{ Max Planck Institute for Meteorology, Germany } & \multirow[t]{2}{*}{ Giorgetta et al. (2013) } \\
\hline & OGCM: approx. $0.4^{\circ}, 40$ & & \\
\hline \multirow[t]{2}{*}{ MRI-CGCM3 } & AGCM: approx. 110 km, 48 & \multirow[t]{2}{*}{ Meteorological Research Institute Japan } & Yukimoto et al. (2011) \\
\hline & OGCM: $1^{\circ} \times 0.5^{\circ}, 50$ & & Yukimoto et al. (2012) \\
\hline
\end{tabular}

caused large biases in simulated daily minimum temperatures in northern winters. Further information will be available at the d4PDF website and others.

\subsection{Large-ensemble simulations ... (2)}

Each subset contains the global and regional model simulations for 29 to 60 years with 50 to 100 different initial and boundary conditions (Table 1). Hence, a total of thousands-year simulations at each warming level provides an ample supply of samples of weather extremes and rare events, as introduced later. The total volume of d4PDF is approximately 2 petabytes. Hereafter, the climate simulations by the global and regional models are referred to d4PDF-G and d4PDF-R, respectively.

Figure 3 displays all experiments of d4PDF-G. Global mean surface air temperatures (SAT) of the d4PDF past simulations display a global warming trend as in the time series of the CMIP5 experiments. By contrast, the SAT time series of the other experiments fluctuate at each warming level. The uncertainties of the future climate simulation are much smaller than those of the six CMIP5 models, because of the adjustment procedure for the future SST trends introduced above. The interannual variations of the d4PDF simulations are mostly the same between each other, since observed internal variations of the ocean boundary conditions are commonly used in all the experiments.

In general, large-ensemble simulations yield robust statistics on both means and extremes. Large-ensemble database d4PDF was designed to be able to estimate future changes in severe weather and climate events occurring rarely, such as heavy precipitation and tropical cyclones, as well as changes in mean climate states. To achieve this, it is furthermore necessary to confirm how well the models reproduce mean climate states and severe events in the past climate simulations.

With d4PDF outputs, users can obtain robust statistics on, for instance, return periods of more than 100 years of heat waves, heavy precipitation, storm surges, etc., which affect social infrastructures, via simple arithmetic computations without any statistical assumptions. Such nonparametric approaches are powerful in both climate and assessments studies. Statistics on events lying close to the tails of the PDF can also be at confidence levels (e.g., Shiogama et al. 2016; Kawase et al. 2016), and spatially or temporally smooth images of characteristics of rare events can be obtained as desired in many cases (e.g., Mizuta et al. 2017; Matsueda and Endo 2017; Yoshida et al. 2017).

Several studies have reported on the ensemble members that are required for attribution of atmospheric phenomena. How many ensemble members is sufficient for robust estimates depends on targets or on temporal and spatial averaging scale. Hibino and Takayabu (2016) demonstrated detectable signals of future precipitation at low, middle, and high latitudes, changing temporal and spatial scales for averaging. With 100 ensemble simulations of MPI-GE, Maher et al. (2019) showed estimation of ensemble sizes needed for isolating forced trends in future sea level pressure from internal variations of large amplitude. For detecting year-to-year variations of annual hurricane frequency forced by SST, Mei et al. (2019) concluded that a twenty ensemble was sufficient, using d4PDF-G.

Figure 4 demonstrates ensemble sizes required for detecting future changes in extremes of annual maximum 1-day precipitation (Rx1d) of d4PDF-R at Tokyo. The histograms of Rx1d become smoother and less uncertain as many ensemble members are used (Fig. 4a). The 


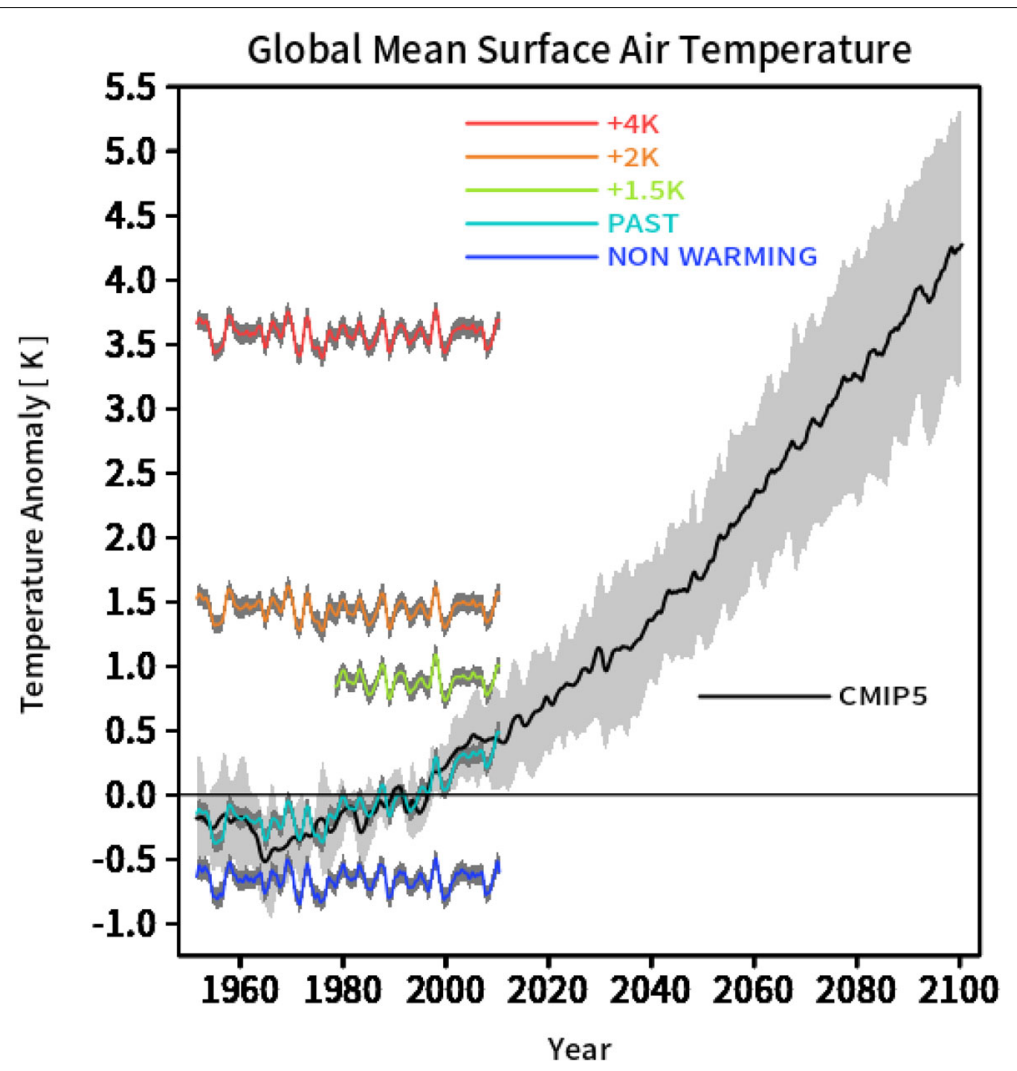

Fig. 3 Time series of global mean surface air temperature anomalies of d4PDF-G for past (light blue), nonwaming (blue), +1.5 K (green), +2 K (orange), and $+4 \mathrm{~K}$ (red) climate simulations and CMIP5 historical and RCP8.5 experiments with six climate models. Shading indicates two-sigma uncertainties. Time series are drawn relative to the averages for the period from 1975 to 2005

Rx1d extremes locating in the thin-tailed PDF somewhat largely depend on the number of ensemble members (blue and red circles along the abscissas). For future changes in 95-percentile Rx1d extremes, the uncertainties are not changed substantially when the members more than 30 are used, while all members should be taken into account for the 99-percentile extremes (Fig. 4b).

\subsection{Attributing extreme and severe events ... (3)}

How well past weather and climate events on seasonalto-decadal time scales are reproduced responding to observed SSTs is one of the key factors when attributing weather or climatic events to global warming. In addition, better reproduction of past climate and severe events should be a minimum requirement for confidence in estimating the future changes because the adopted model physics has been proven feasible for the present climate system of the earth. Moreover, high-resolution and largeensemble members of climate simulation help reduce uncertainties in estimates of atmospheric responses to anthropogenic forcing and given SST variations.

Prior to d4PDF, MRI-AGCM3.2 was applied to timeslice experiments using the same model setups as in
d4PDF; however, a different experimental design was adopted before, particularly with respect to lower boundary conditions: a different SST and SIC analysis of HadISST (Rayner et al. 2003) used, and no SST and SIC perturbations given (Mizuta et al. 2012). Through these experiments, model climatology was confirmed to be sufficient to reproduce observed distributions of precipitation and tropical cyclone genesis, as reported by Mizuta et al. (2012) and Murakami et al. (2012). Figures 5 and 6 are drawn using d4PDF-G and indicate that the past climate simulations are almost identical to those of the former studies quantitatively.

The global model outputs of d4PDF for the past 60 years have been examined in many studies, focusing on extreme events of SATs and precipitation and typical atmospheric phenomena. These studies reported the reproducibility of the past climate by MRI-AGCM3.2 in various points of view. Shiogama et al. (2016) most early conducted a study with d4PDF-G. They attributed historical changes in daily temperature and precipitation extremes to global warming and pointed out that spatial distributions and anthropogenic impacts of record-breaking events are sensitive to climate models and boundary conditions used in 

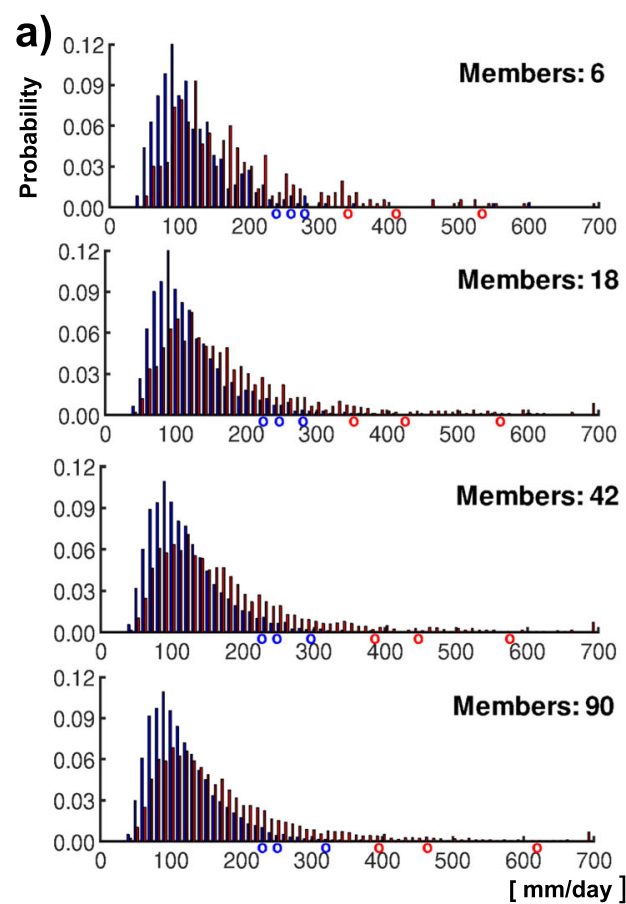

\section{b)}

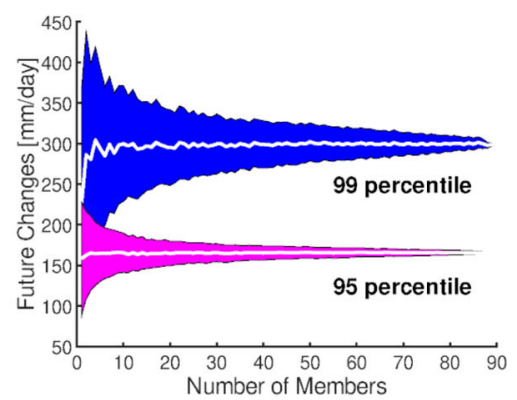

Fig. 4 a Histograms of annual maximum 1-day precipitation ( $\mathrm{mm} /$ day) of each year in the past (blue) and $+4 \mathrm{~K}$ (red) regional climate simulations (d4PDF-R) at Tokyo, for cases of a certain set of 6, 18, 42, and 90 members as aligned from the top to the bottom. Members plotted are chosen evenly from 15 simulations with six different SST trends. Colored circles along the abscissas in each histogram indicate positions at the 95, 97, and 99 percentiles for past (blue) and +4 K (red) climates. b The mean future changes (line) and the one-sigma uncertainties (shade) in the 95 (red) and 99 (blue) percentile maximum daily precipitations estimated nonparametrically from the database

the experiments. Endo et al. (2017) examined monsoonal precipitation in East-Asian summer and confirmed a good agreement of climate (Fig. 5), daily strong precipitation, and atmospheric circulations with corresponding satellite observations and reanalysis. Duan et al. (2019) had another comparison study with the d4PDF-G precipitation and station data over China. They obtain rather high correlation coefficients above 0.7 between d4PDF-G and ground-based observations for all seasons in China, and a maximum of 0.93 for spring. The frequency of the modelgenerated tropical cyclones (TCs) agrees with the observations (Fig. 6; Yoshida et al. 2017). For example, a correlation coefficient between d4PDF-G and the observations is 0.84 for time series of annual hurricane frequency in the North Atlantic basin for recent decades (Mei et al. 2019). However, the model-generated TCs are generally weak (Fig. 6b). By correcting simulated wind speeds (Sugi et al. 2017), Yoshida et al. (2017) showed a realistic distribution of occurrence frequency of very intense TCs (categories 4 and 5), and the future changes for the late twenty-first century agree with Knutson et al. (2015). Note that the SST-forced AGCM abnormally enhances tropical cyclones because of the lack of air-sea interaction (Ogata et al. 2016), although the genesis frequency agrees well with the observations at midlatitudes (Fig. 6c).
According to studies with d4PDF-G, MRI-AGCM3.2 is superior in reproducing atmospheric phenomena in response to tropical SST variations, in particular, El Niño and Southern Oscillation (Ueda et al. 2018; Xie et al. 2018), and decadal climate variations such as Pacific Decadal Oscillation (PDO), Interdecadal Pacific Oscillation (IPO; Imada et al. 2017), and Atlantic Multidecadal Oscillation (AMO) (Kamae et al. 2017a). A couple of researches reported reproducibility of specific atmospheric phenomena: Northern Hemisphere blocking (Matsueda and Endo 2017) and atmospheric river (Kamae et al. 2017b). In addition, the large-ensemble members yield robustness of atmospheric responses forced by observed SSTs together with probabilistic information (Kamae et al. 2017b; Mei et al. 2019; Yoshida et al. 2017), and reduce atmospheric noise (Kamae et al. 2017b). Using the nonwarming simulations, contributions from anthropogenic radiative forcing and observed SSTs are successfully isolated from signals in the past climate simulation. Imada et al. (2017) confirmed that enhancement of warm summers and cold winters after year 2000 in Japan resulted from atmospheric anomalies associated with a decadal La Niña-like condition of IPO, separating anthropogenic warming, implying that future heat wave risks in summer and autumn over Japan will intensify by 


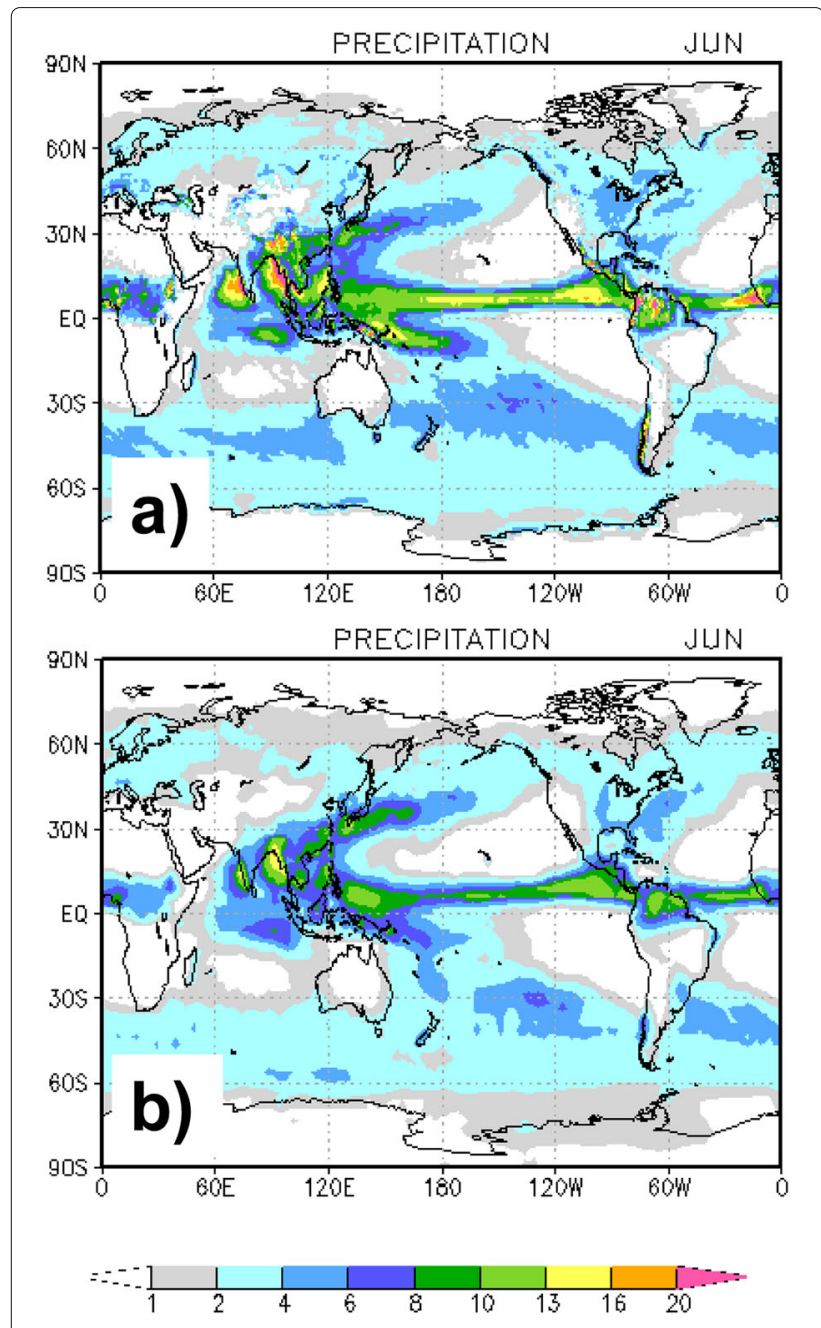

Fig. 5 a Precipitation climatology $(\mathrm{mm} /$ day) for June in the past climate simulations of d4PDF-G and $\mathbf{b}$ corresponding observations (GPCP; Adler et al. 2003)

a coincidence of global warming and a decadal phase of tropical Pacific conditions. Similarly, Kamae et al. (2017b) examined summer climate over western North America forced by radiative forcing response and showed the internal decadal variations depending on phases of $\mathrm{AMO}$ and PDO.

The large-ensemble and high-resolution outputs support studies approaching mechanisms of the climate system. The model simulations resolve, for example, the tropical precipitation system (Xie et al. 2018), tropical cyclone activity (Ueda et al. 2018), and internal atmosphere-land interactions (Sato and Nakamura 2019). Recent observations suggest arctic warming instigates Eurasian cold anomalies in winter. This is sometimes referred to as Warm Arctic/Cold Eurasian (WACE; Mori et al. 2014). Hori and Oshima (2018) studied WACE using the past and nonwarming simulations and presented one sight of the recent trend in WACE associated with the Arctic warming.

Regional model NHRCM has an advantage in reproducing spatially detailed climate states in the East Asian region, which are highly required by assessment studies. Higher-resolution regional models perform better in representing heavy precipitations, resolving complex topography, coastal lines, and dynamical process on mesoscales (Giorgi 2019). The model of the $20 \mathrm{~km}$ spatial resolution used in d4PDF satisfactorily simulated temperature and precipitation variations on the daily time scale (Nosaka et al. 2020; Takayabu and Hibino 2016). In addition, the global model provided NHRCM with good-quality lateral boundary conditions for dynamical downscaling. The model having detailed topography shows SAT and precipitation climatologies (Nosaka et al. 2020), snow coverage (Kawase et al. 2016), and extreme precipitation (Hatsuzuka and Sato 2019; Osakada and Nakakita 2018b) more realistically than the global model. Meanwhile, seasonal biases unavoidably exist in the NHRCM simulations. Assessment studies often require unbiased inputs of atmospheric variables on local and short-term scales, whereas any methodologies do not always satisfy the requirements. Watanabe et al. (2020) proposed a bias correction method specifically designed for largeensemble data, and they demonstrated how to obtain less erroneous estimates of hydrographic extremes.

Nonwarming simulations with both global and regional models are available in d4PDF. This is a quite unique feature of d4PDF. Examining climate states together with the nonwarming simulations provides an additional interpretation of past climate variations. Typically, this explains the extent to which anthropogenic forcing affected the weather and climate events by comparing the past and nonwarming climate simulations, as shown by the aforementioned studies (Imada et al. 2017; Kamae et al. 2017b; Shiogama et al. 2016). If one focuses on a specific weather event, the approach is often termed event attribution (EA) technique. The American Meteorological Society have issued annual special reports collecting materials on world-wide extreme events (e.g., Herring et al. 2019), in which the EA technique is widely used. An EA study with d4PDF was conducted on the 2018 heat wave event in Japan (Imada et al. 2019). In general, severe events accompanying anomalous precipitation over Japanese Islands are hardly attributed by global model outputs owning to the lack of resolution for topographic complexity, mesoscale dynamics and physics, and so on. Therefore, the nonwarming simulations by NHRCM created a new value in interpreting regional climate systems under global warming. An EA study for a heavy precipitation event occurring in Japan is currently conducted. Another study with the regional nonwarming simulations by Kawase et al. (2019) found a topographic contrast of 


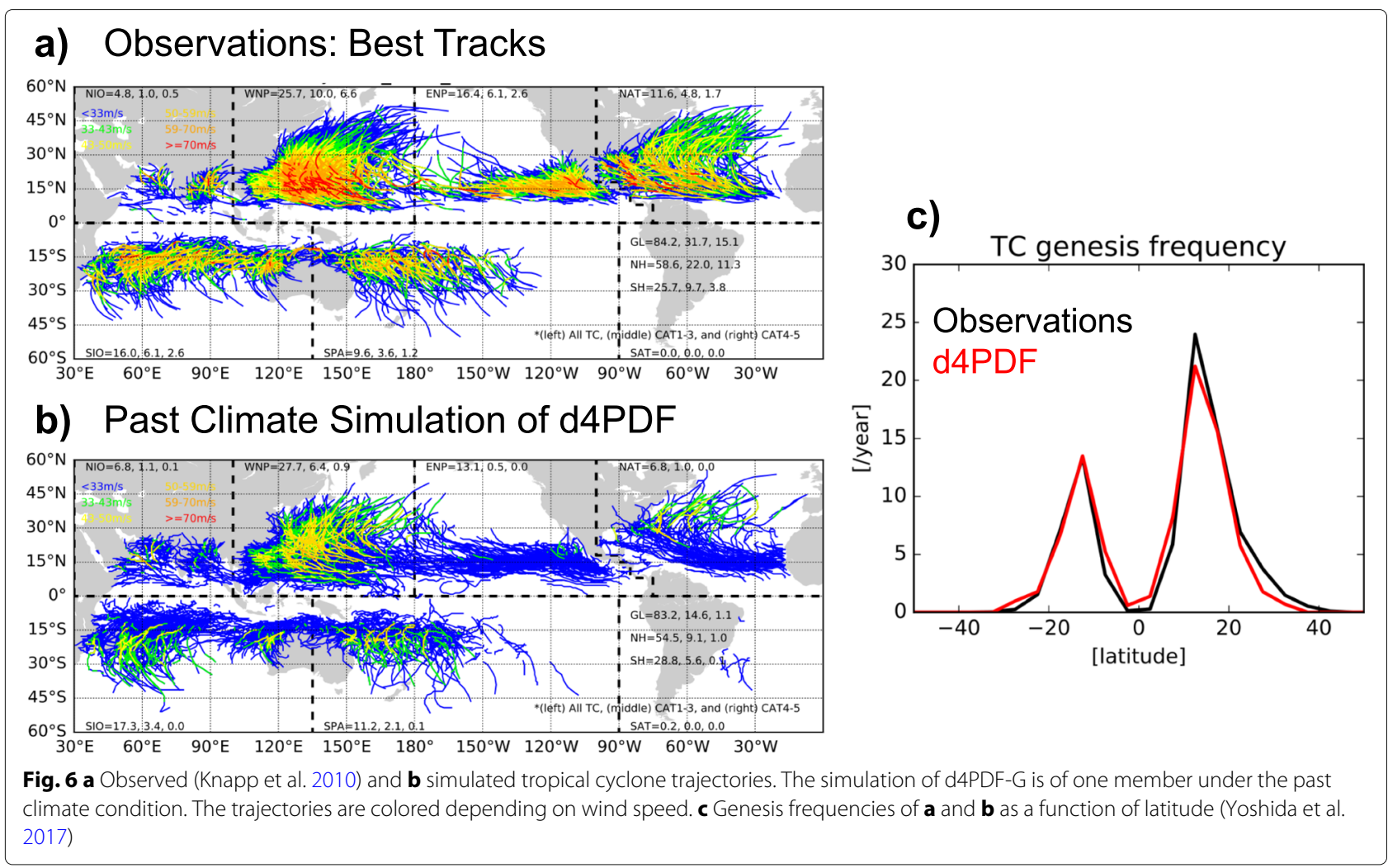

global warming impacts on regional climates on a southern island of Japan, which is called Kyushu island. Namely, the area of the island is about $37,000 \mathrm{~km}^{2}$, and ranges of mountains in the island cause different impacts of global warming on synoptic phenomena between the western and eastern parts of the island.

\subsection{Global future climate changes ... (4)}

Future $+1.5 \mathrm{~K},+2 \mathrm{~K}$, and $+4 \mathrm{~K}$ climates treated in $\mathrm{d} 4 \mathrm{PDF}$ correspond to those around 2030, 2040, and 2090, respectively, under the CMIP5 RCP8.5 scenario (Fig. 3). The database exhibits detailed view of future changes particularly in atmospheric extremes because its resolution is twice as high as those of the CMIP5-participating models. Because of the large number of ensemble members available in the database, future changes obtained by simple arithmetic computations are statistically robust in most cases. As mentioned in the previous section, the reproducibility of past weather and climatic events is necessarily confirmed in the past climate simulations for reliable estimations of future climate changes.

The database contains many samples of rare weather and climatic events concerned by risk assessment studies. Using global model outputs, future changes in tropical storm (Yoshida et al. 2017), blocking (Matsueda and Endo 2017), atmospheric river (Kamae et al. 2019), and precipitation extremes (Duan et al. 2019; Endo et al. 2017) have been examined. In these studies, rare events sampled from past climate simulations were compared with the observations, and the future changes were judged to be robust, however not necessarily for all aspects of the targets. One scientific finding is that very intense tropical cyclones (categories 4 and 5) will occur more frequently in elongated areas from the south of Japan to Mexico via Hawaii compared to those under the past climate conditions (Yoshida et al. 2017). As a result, heavy precipitation, 90- and 99-percentile values of daily precipitation, will possibly increase in these regions as discussed by Kitoh and Endo (2019) who examined precipitation extremes in the tails of PDF separately for tropical cyclones and synoptic events.

Further, the slow translation speed of tropical cyclones would possibly cause high disaster risks due to longterm heavy rainfall. Whether translation speeds of past and future tropical cyclones reduce is a current recent research topic. Yamaguchi et al. (2020) showed a 10\% slowdown at midlatitudes in the $+4 \mathrm{~K}$ climate scenario of d4PDF-G because of weakening westerly winds due to the decrease in baroclinicity in the future atmosphere; however, no signals were found in the past climate simulation, which is different from an observational study (Kossin 2018). Kanada et al. (2020) also reported a similar slowdown (about 13\%) of future TCs passing east of Japan by conducting further dynamical downscaling experiments 
from d4PDF-R with a high-resolution $(4 \mathrm{~km})$ nonhydrostatic regional model called the Cloud Resolving Storm Simulator (CReSS).

Future climate simulations involve uncertainties caused by the different future SST warming patterns and the perturbations of initial and lower boundary conditions. The six SST trend patterns caused some varieties of future changes in frequencies of blocking events that can cause abnormal weather (Matsueda and Endo 2017), atmospheric river that can cause serious floods (Kamae et al. 2019), and North-Pacific clear-air turbulence concerned by aircraft pilots (Watanabe et al. 2019). Using a conventional approach for detecting SST-forced signals (Rowell et al. 1995; Sugi et al. 1997), Endo et al. (2017) obtained a conclusion; climatological mean changes in annual maximum 1-day precipitation amounts over Japanese Islands are affected by uncertainties originating equally from the two sources of uncertainty with respect to external forcing and internal variability, whereas internal variability is the major source of uncertainty in those over inland China. This contrast between future changes over Japan and China is likely affected by future tropical cyclone activity modulated under the six different climate conditions (Ide et al. 2018).

\subsection{Regional future climate changes ... (5)}

The climate simulations of d4PDF-R are helpful to evaluate future changes in mean climatological states and rare events governed by mesoscale dynamics and physics, resolving topographical effects over Japan. As Nosaka et al. (2020) summarized, future changes in SATs are larger in higher latitudes during both winter and summer. These latitudinal contrasts are possibly due to reducing snow cover and prescribed ocean warming. Precipitation changes appear large on the Pacific side both during winter and summer owing to weakening monsoonal circulations.

Heavy snowfall particularly on the Sea-of-Japan side of Japanese Islands is caused by strong winter monsoon winds across the warm ocean. Kawase et al. (2016) reported increased heavy daily snowfall in central Japan even in the future $+4 \mathrm{~K}$ climate. Owing to global warming, the occurrence of snowfall reduces particularly in coastal areas. However, heavy snowfall appears to be intensified at high altitudes, where temperatures are subzero, accompanied by enhanced polar air mass convergence over the Sea of Japan (Nagata et al. 1986). Recently, Kawase et al. (2020) obtained more detailed images of future snow cover changes particularly for mountainous areas with dynamical downscaling by NHRCM of $5 \mathrm{~km}$ and $1 \mathrm{~km}$ resolution.

Japan has a rainy season called Baiu lasting from June to July, which accompanies a frontal structure and strong precipitations particularly in the latter half of the season. Osakada and Nakakita (2018a) and Nakakita and Osakada (2018) studied future change in the frequency of heavy rainfall during Baiu. Two studies commonly confirmed that the frequency of extreme rainfall events in Baiu will increase in the future simulations of d4PDF-R. In particular, the former study focused on changes in typical atmospheric synoptic patterns and reported that Baiu heavy rainfall events mainly occur in western Japan in the past climate; however, the areas extended eastward in future climates with increasing trends of accumulated precipitation amount per rainfall event.

Information engineering approaches are effective for handling large gridded data. A method of self-organizing maps (SOM) was applied to detecting future changes in extreme rainfall during the Baiu season (Ohba and Sugimoto 2019) and heavy snowfall in Japan (Ohba and Sugimoto 2020; Ohba and Kawase 2020) related to synopticscale weather patterns. Another study by Matsuoka et al. (2019) proposed a neural network system for extract stationary fronts over Japan from d4PDF-R weather variables.

Heavy precipitation events induced by tropical cyclones are frequently observed in Japan. Due to the lack of consensus on future changes in tropical cyclone (TC) activity reported in the IPCC Fifth Assessment Report (Working Group I; Stocker et al. 2013), it is not easy to conclude how much TC-induced accumulated precipitation amounts change in the future on average. However, it is valuable to examine changes in extreme precipitation due to TCs as Hatsuzuka et al. (2020) did. They tried to find a relationship between TC intensity and 90th percentile values of maximum daily precipitation of more than 4000 TC samples taken from the d4PDF simulations. Consequently, the strong precipitation amounts increase in the future, and there is no meaningful relationship between precipitation extreme and TC intensity except in areas with wind-facing slopes. However, a future increase in TC-induced precipitation amount is expected due to the aforementioned slowdown of TCs at midlatitudes.

\subsection{Scalability in future climate changes ... (6)}

Using simulations at three or four levels of warming in the past and future climate conditions, several studies investigated the relationships between future changes in climate variables of interest and increases in global mean SAT. If the former vary linearly with the latter, the climate system is considered scalable. In this case, the system is rather simple in terms of effects of global warming. Otherwise, some nonlinear mechanisms have to be considered. In addition, scalable relationships help us determine future changes at any warming levels without additional model simulations. 
Fujita et al. (2019) compared future changes in precipitation indices between $+2 \mathrm{~K}$ and $+4 \mathrm{~K}$ simulations separately for wet and dry seasons across the globe using d4PDF-G. Nosaka et al. (2020) investigated the scalability of various aspects in future regional climate changes using simulation results at four warming levels of d4PDF$\mathrm{R}$. In many cases, future changes of climatological states and extremes have scalability. According to these studies, increasing rates of heavy precipitation to temperature change mostly agree with the Clausius-Clapeyron rate $(7 \% / K)$ although they sometimes depend on regions and seasons (Nosaka et al. 2020). For rare events located at the tails of probabilistic distribution functions, scalability may not always be possible. With regard to tropical cyclones, the genesis frequency for all categories is scalable; however, scalability is unlikely for categories 4 and 5 (Yoshida 2019, pers.comm.).

\subsection{Assessment of risks due to heavy precipitation and river flooding ... (7)}

Climate change caused by global warming is expected to have a major impact on extreme water-related hazards. Specifically, Baiu-related heavy precipitation and typhoons are major natural disasters in East Asia (Mori and Takemi 2016; Nakakita and Osakada 2018; Osakada and Nakakita 2018a). To assess the impact of heavy precipitation and typhoons, quantitative large-ensemble projections are critically important to capture intensity and the numbers of events. Therefore, d4PDF is applicable for extreme hazard projections and related impact assessments. Here, we review typical natural hazard studies using d4PDF in both English and Japanese language journals.

Tachikawa et al. (2017) projected future changes of d4PDF-R in extreme river discharge for three major basins in Japan. Figure 7 shows the nonexceedance probabilities of river discharge. The 1/200-year occurrence probability events for the annual maximum $24 \mathrm{~h}$ rainfall of the $+4 \mathrm{~K}$ simulations in major river basins of Japan are 1.3 to 1.4 times larger than those of the past climate simulations. Therefore, they concluded that, in general, changes that are 1.5 to 1.7 times larger are expected for annual maximum river discharge over Japan. The 200-year annual maximum $24 \mathrm{~h}$ rainfall event in the $+4 \mathrm{~K}$ future climate is equivalent to the 900-year event in the past climate simulation. Hence, the return period of future extreme river discharge will significantly decrease (more frequent) due to climate change. Such analyses relevant to extremes are possible using the large ensembles without statistical hypothesis. Similar results were obtained in different river basins in Japan and other countries: the Nagara river basin by Harada et al. (2018), the Hokkaido region by Kimura et al. (2018) and (Masuya et al. 2018), and Indochinese Peninsula by Hanittinan et al. (2018).
In SI-CAT, several dynamical downscaling studies for spatially refined risk assessments were performed with NHRCM of $5 \mathrm{~km}$ resolution. The $5 \mathrm{~km}$ model resolves hourly changes of precipitation with complex topography (Murata et al. 2017). Uemura et al. (2018) demonstrated the impact of the downscaling on river discharge in Hokkaido. In general, the $5 \mathrm{~km}$ NHRCM gives better results than the $20 \mathrm{~km}$ NHRCM, but these are not always enough for impact assessment in areas of complex local topographies and any basin sizes. The projections for disaster assessment of extreme river flooding caused by Baiu and typhoon events using d4PDF revealed that future river discharges significantly change in highly urbanized basins in Japan and Asia as follows. Hoshino and Yamada (2018a) analyzed spatiotemporal distributions of annual maximum rainfall in the Tokachi River basin in Hokkaido and reported that the annual maximum heavy rainfall will be spatially concentrated in the future climate. Furthermore, Hoshino and Yamada (2018b) expanded their analysis to the first-class rivers, which are directly managed by the central government, using d4PDF-R. They found that annual maximum precipitation amounts averaged in each basin increase in the future whose increasing ratios depend on geographical locations, and suggested usefulness of d4PDF for analysis of precipitation extremes, serious river flood disasters of the more frequent future extremes, and the necessity of flood control measures. Figure 8 shows that future changes in the first-class river basin averaged 60-year maximum precipitation in Japan, and statistically significant increases in basin-averaged precipitation ranging from 10 to $30 \%$ appear in northern Japan. Another study by Watanabe and Utsumi (2018) presented the regional characteristics of precipitation based on a clustering approach, highlighting the accuracy of clustering classification and frequency for precipitation. These river-basin-based analyses associated with heavy precipitation using the d4PDF-R downscaling are useful to discuss the future changes in river discharge or flood risks.

The projection of extreme river flooding is directly applicable to adaptation or economic risk analysis. Tokioka et al. (2018) examined different countermeasures for devising a flood control plan as a case study of the Hokkaido region. In addition, Tanaka et al. (2018) studied flood risks via probabilistic rainfall modeling targeting the Yodo River basin in Japan. Figure 9 shows the exceedance probability of the economic damage caused by the flooding of the Yodo River based on d4PDF-R. The economic damage caused by flood risk is clearly higher in the +4 $\mathrm{K}$ climate condition. This increase in risk is caused by the increased frequencies of heavy rainfall in this river basin. Furthermore, the variability of the damage caused by floods increases as the probability of their occurrence decreases. Combining the probabilistic rainfall model 


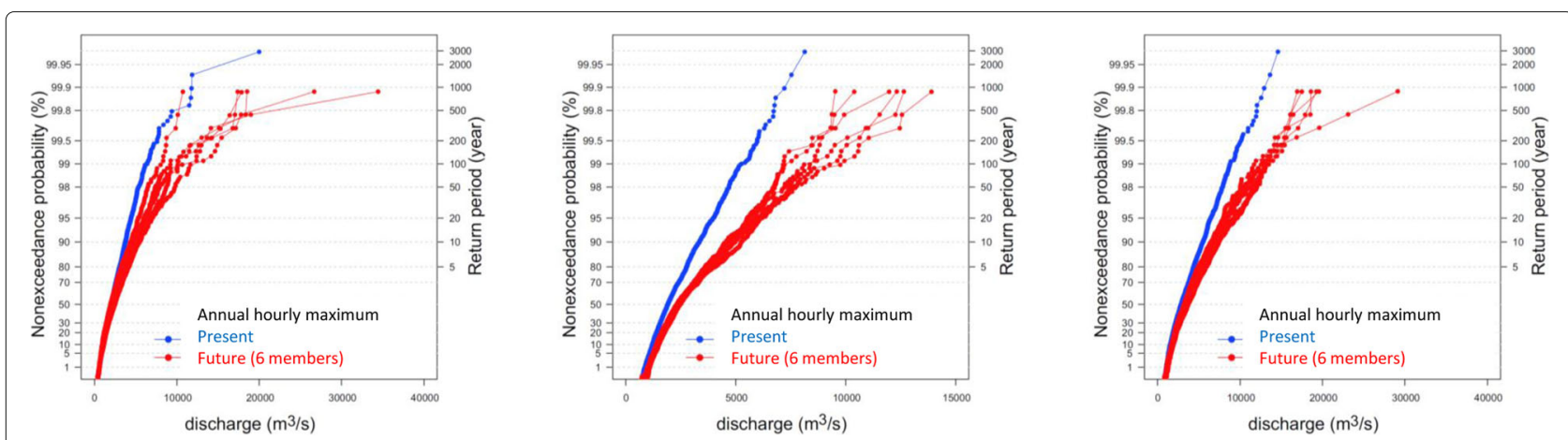

Fig. 7 Nonexceedance probabilities of river discharge for three major rivers in Japan (left: Arakawa river, middle: Shonai river, right: Yodo river; blue: past climate, red: $+4 \mathrm{~K}$ climate) based on d4PDF-R, after Tachikawa et al. (2017)

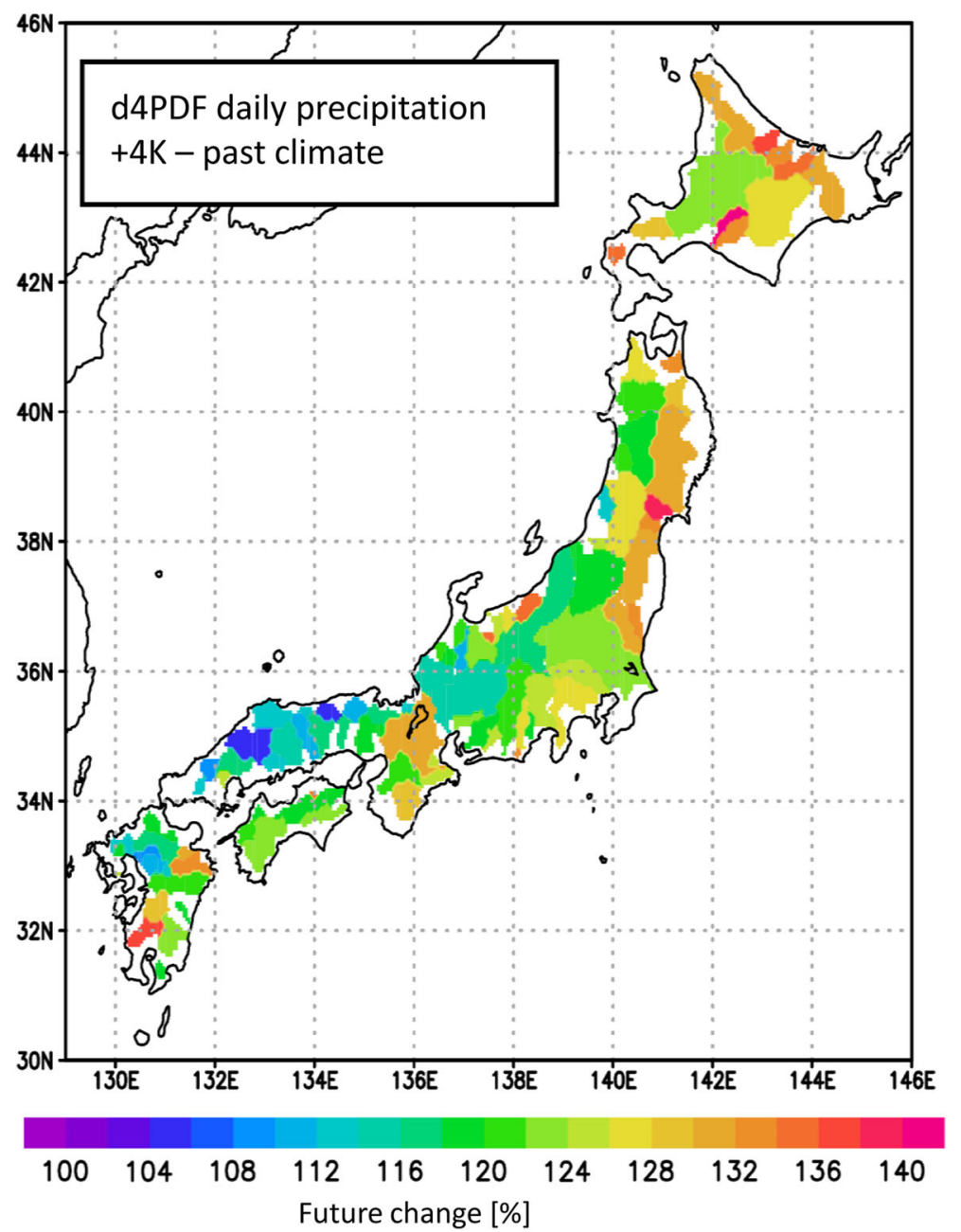

Fig. 8 Future changes in the maximum precipitation averaged over the first-class river basins (future minus past, unit: \%), after Hoshino and Yamada (2018b) 


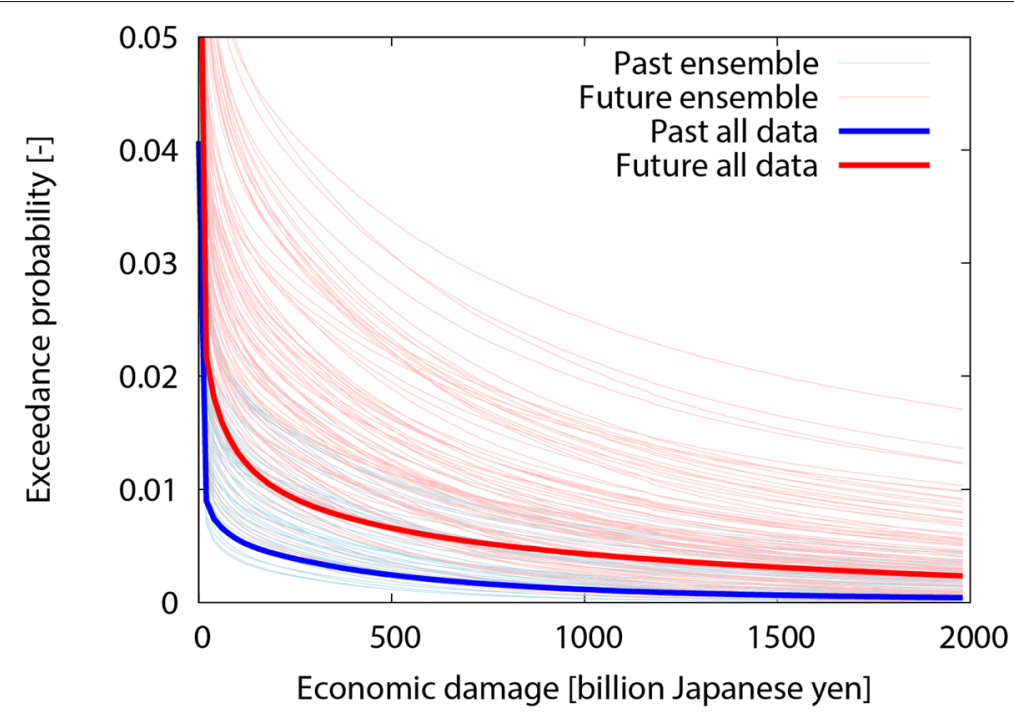

Fig. 9 Exceedance probability of economic damage to Yodo river flooding by d4PDF-R (past: blue, future: red), after Tanaka et al. (2018)

and large-ensemble climate data, process-based ensemble flood risk curves are derived without assuming any parametric error distributions.

The large ensemble helps in developing statistical methods for river flood risk assessment studies. Kim et al. (2017) developed a statistical downscaling technique for precipitation based on d4PDF-G. The statistically downscaled results show a plausible mimic to the $20 \mathrm{~km}$ AGCM output (Mizuta et al. 2012) in the frequency of daily precipitation amounts, which can be applied to statistical weather generator systems. Meanwhile, Watanabe et al. (2018) applied two bias correction methods for hourly precipitation to d4PDF-R. The overestimation bias in precipitation was reduced by the bias correction, and the probability of historical extremes was reproduced in biascorrected outputs. A similar bias correction method was examined for the cumulative rainfall duration by Kojima et al. (2018). Furthermore, Kitano et al. (2017) used d4PDF precipitation data for validating an extreme value theory. They demonstrated an advantage of using large ensemble for the convergence of extreme values, which cannot be validated by observed data owing to the limited number of samples. Kuzuha and Senda (2018) performed an uncertainty of extreme value analysis for 100 -year precipitation around Japan.

\subsection{Assessment of coastal risks ... (8)}

The projection of future changes in storm surges is important for estimating the risk of coastal flooding. As severe storm surges excite depending on the combination of the tropical cyclone intensity, translation speed, and track to a particular bay, their probability of occurrence is expected to be equal to or less than once per 100 years. Unless large- ensemble simulations were available, probabilistic determination of the occurrence of tropical cyclone-induced storm surges is difficult. Mori et al. (2019) projected future changes in regional storm surges targeting Tokyo and Osaka Bays using d4PDF. The projected storm surge heights in Tokyo and Osaka Bay will increase by 0.3 to 0.45 $\mathrm{m}$ for a 100-year event. Mori et al. (2019) indicated that both frequency and intensity changes of tropical cyclones will significantly give impacts on storm surge heights. The increase in 100-year storm surge height was first discussed in the IPCC special report on the Ocean and Cryosphere in a Changing Climate (SROCC; Pörtner et al. 2019). Similar case studies were conducted for the Korean Peninsula by Yang et al. (2017) and for Bangladesh by Al Mohit et al. (2018). For example, Fig. 10 shows the projection of future storm surge heights at Yeosu in Korea (Yang et al. 2018), clearly demonstrating that the confidence intervals become narrower as the number of ensembles increases. Winter extratropical cyclones also generate storm surges and storm waves in the Sea of Japan. Taka et al. (2018); Taka et al. (2019) analyzed changes in winter extratropical cyclones using d4PDF-R. The intensity of the strongest extratropical cyclones will increase by approximately 12 $\mathrm{hPa}$ in the $+4 \mathrm{~K}$ climate; however, the climatological average will remain unchanged. The tracks of extratropical cyclones will also be shifted northeastward, and the number of events will decrease on the main island of Japan, as shown in Fig. 11.

In the meantime, extreme ocean waves is important for the coastal, ocean, and environmental engineering. As a first step, the future projections of the global wave climate under a global warming scenario using a dynamical wave model were conducted by Shimura et al. (2015); Shimura 


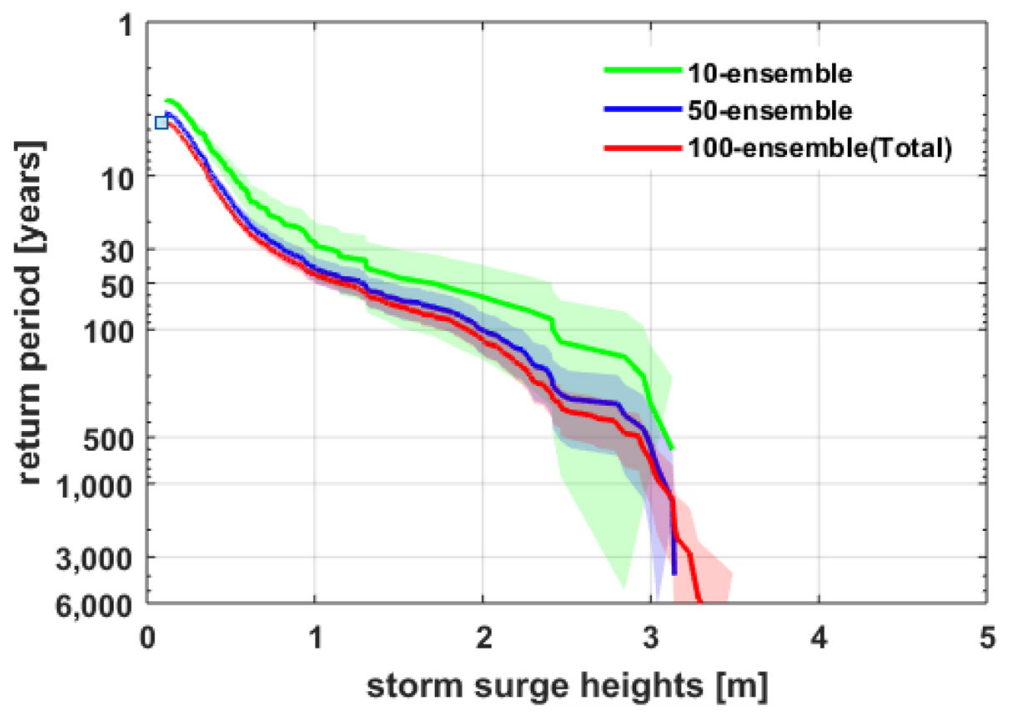

Fig. 10 Projection of future storm surge heights at Yeosu, Korea (10 ensembles: green, 50 ensembles: blue, 100 ensembles: red, shade indicates the 95\% confidence intervals), based on d4PDF-R, after Yang et al. (2018)

et al. (2016); Shimura et al. (2017) and Morim et al. (2019). Robust changes in wave characteristics are projected over large sectors off of the world's coasts (covering approximately $50 \%$ of the coastline; Morim et al. 2019). In the western North Pacific region, future projected changes in summertime mean wave heights, which are influenced by tropical cyclone (TC) changes, significantly vary depending on the spatial SST pattern over the tropical Pacific. Future projections of 10-year return period wave heights generated by TCs show both increases and decreases from the past climate ranging from $\pm 4 \mathrm{~m}$ for different regions over the ocean (Shimura et al. 2015).

For using the model-generated TCs for coastal assessment studies, Ide et al. (2018) conducted a spatially detailed analysis for the future TC characteristics in the western North Pacific sector, applying a bias correction of TC intensity similar to Sugi et al. (2017). They showed a large uncertainty in minimum surface pressure changes among the future SST trend patterns. This should be paid attention to when applying d4PDF's TCs to impact assessments of future storm surges in this region. Webb et al. (2019) focused on TCs in the Southern Hemisphere and developed a TC tracking method which well resolves TC decay latitudes necessary for coastal impact assessments even at middle-to-high latitudes. The statistical characteristics of observed TCs needed by impact assessments are rather poorly known, whereas d4PDF enables us to assess hazards related to TCs, as seen above. In addition, the use of TCs in the large-ensemble simulations could improve stochastic

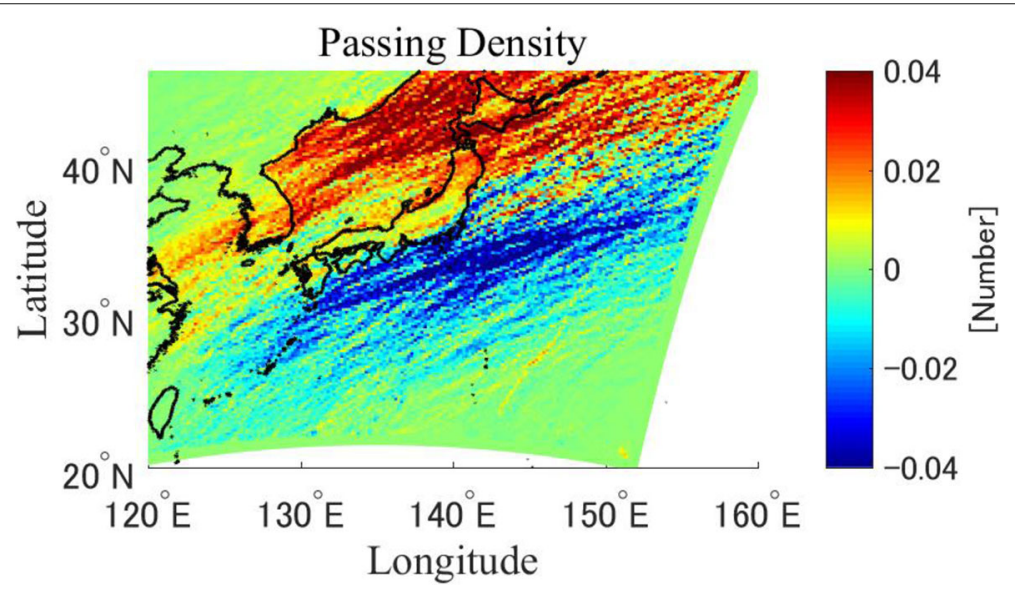

Fig. 11 Future changes in severe winter storm tracks around Japan, based on d4PDF-R (future minus past, unit: numbers per year in each $1^{\circ}$-longitude and $1^{\circ}$-latitude box), after Taka et al. (2018) 
TC models commonly used in engineering fields (Umeda et al. 2019).

\subsection{Other risk assessment topics ... (9)}

The impact of climate change on water resources and agriculture is essential not only to reduce negative consequences but also to increase opportunities. Iizumi et al. (2018a) estimated economic production losses for major crops at a global scale during the period from 1981 to 2010 , relative to those observed in the early twentieth century, based on the d4PDF-G past and nonwarming simulations. The crop yield simulation demonstrated significant decreases at lower latitudes as well as significant yield increases at higher latitudes. Furthermore, Iizumi et al. (2018b) summarized agricultural research topics for climate change adaptation. Kim et al. (2018) conducted a survey of climate change impact on heating and cooling system for air conditioning by targeting Yokohama Minatomirai 21 Area, Japan. They showed that electric power consumption will increase to more than $140 \%$ in the $+4 \mathrm{~K}$ climate scenario.

The use of large-ensemble climate simulations such as $\mathrm{d} 4 \mathrm{PDF}$ is a big challenge for impact projection and assessment, whereas increasing the number of ensembles makes it difficult to use process models because of limited data storage and computational resources. A novel data service system developed by Nakagawa et al. (2020) could be a solution to the problem, by which data users access and download the data of minimum requirement. Also, the system helps realize an integrated system for impact, adaptation, and vulnerability models highly desired together with the ensemble projections.

\subsection{Social Implementations ... (10)}

The extreme natural hazards estimated from a number of climate extremes in d4PDF showed significant future changes. It is important to apply these estimates to adaptation, implementation, and policy decisions. The Japanese central government released a report entitled "National Plan for Adaptation to the Impacts of Climate Change" on November 25, 2015, which triggered the movement of climate adaptation in Japan (Ministry of the Environment 2018).

Since the release of d4PDF in 2015, the central and local government agencies of Japan have started to pay attention to climate simulation products and $\mathrm{d} 4 \mathrm{PDF}$. The first real application of d4PDF was an emergent river flood control management policy at Hokkaido in 2017 in response to typhoon-induced severe river flooding in the summer of 2017. Since 2018, the technical committee of the Ministry of Land, Infrastructure, Transport and Tourism (MLIT) of Japan mainly uses d4PDF for future river flood control management and released revised technical implementation of heavy precipitation in October 2019 (MLIT 2019). Furthermore, MLIT released a new policy of flood control agenda considering climate change based on the above discussion (MLIT 2020). The interministerial committee of MLIT, Ministry of Agriculture, Forestry and Fisheries (MAFF), and Forestry Agency was established in October 2019 for discussing climate change impact and adaptation along Japanese coasts (MLIT and MAFF 2020). A study of adaptation measures for coastal defense has begun at the central governmental level. Furthermore, Osaka Prefectural Government started to discuss a construction plan for rebuilding three major storm surge barriers along the Osaka Bay Area. The construction of this new gate will begin around 2022 to withstand future storm surges and sea level rise up to 2100 . The technical council of river structure in Osaka Prefecture started to analyze long-term typhoon characteristics derived from d4PDF for coastal gate design (Osaka Prefecture 2020). This will be the first case of climate scenario application to large-scale infrastructure designed in Japan. Although real applications will increase, technical engineering and scientific support will be highly demanded by governmental agencies for conducting national projects requiring a large budget and other resources.

In addition to governmental applications, d4PDF contributes to climate education. Kumamoto Prefecture Environment Center setup interactive display of "Global warming and climate simulation" based on d4PDF. It is essential that both public and young students understand the risks of climate change.

\section{Conclusions}

The large-ensemble and high-resolution climate simulation database called d4PDF was developed for extensive use in impact/risk assessment and policy decision-making for adaptation measures. Since the first data release at the end of 2015, it has become a common future scenario used to realize adaptation measures in Japanese administrations and agencies. Researchers working on global warming have actively incorporated d4PDF in their studies. Consequently, d4PDF has contributed toward the formation of an interdisciplinary research community on global warming across Japan. Through the discussion in this community, physical climate science is expected to satisfy the needs of risk assessments (Sutton 2019).

Large-ensemble climate simulation studies have advanced our understanding of past and future climate changes and have provided statistical reliability for assessing the impacts of significant weather and climatic phenomena in the future. Among impact assessment studies, there has been a "paradigm shift" from parametric statistical approaches to nonparametric approaches. Namely, only by incorporating simulation results directly into impact assessment models, it became possible to 
evaluate risks for the largest class of hazards with return periods exceeding thousands of years, as well as develop useful materials when considering adaptation measures.

Although d4PDF comprises climate simulations at several warming levels with uncertainties in the future projections of the CMIP5 participating models, its range of uncertainties is limited. It may be desirable to consider the uncertainties of climate prediction experiments using multiple physics, multiple models, and more social development scenarios. There is room for ingenuity in experimental setups. However, because it is not easy to encompass all uncertainties by a single research group, a realistic approach is to provide value-added information that incorporates the knowledge and results of existing researches. An alternative solution is a multi-model intercomparison under an international collaboration as CMIP (Sutton 2019).

Missing air-sea interaction in climate simulations is critical in some cases. This tends to intensify tropical cyclones (e.g., Ogata et al. (2016)) and fails to present a strong air-sea interaction between rainfall and sea surface temperature east of the Philippines (e.g., Duan et al. 2008; Kobayashi et al. 2005). Nonetheless, one of the biggest challenges of future climate prediction in Japan is to account for uncertainties in future ocean changes. Surrounded by the Kuroshio, the Oyashio, and the closed seas: the Sea of Japan and the Sea of Okhotsk, each of which has complex variations, the past climate over Japan was affected largely by these. The axis of Kuroshio locates closely along $35^{\circ} \mathrm{N}$. However, those in the model simulations are shifted north in many models, because the resolution adopted by most CMIP5 climate models is too coarse to resolve the regional atmosphere and ocean climates in this region. As a result, future changes in model-generated SSTs among the six CMIP5 models show a large variety in seas around Japan (Fig. 12). For the above reasons, the future changes in SST around Japanese Islands are seen as lack in persuasiveness. Unless we correctly understand details of the future oceanic changes, reducing true uncertainties in climate changes over Japan cannot be realized. Information on ocean warming is also strongly needed for policy decision-making in this country. Now, it is important to take a step toward constructing a new database in which future states of atmosphere and the oceans are physically consistent.

Practically, the outputs of regional atmospheric model are used frequently. User demand for spatiotemporal resolution is extremely high. Such regional climate data are hopefully defined on the same grid as that of the National Land Numerical Information of a typically $1 \mathrm{~km}$ mesh issued by the Ministry of Land, Infrastructure, Transport and Tourism, Japan. Similar products as d4PDF are available for the Japanese domain of $5 \mathrm{~km}$ and 2 $\mathrm{km}$ meshes (Murata et al. 2017), although the ensemble sizes are restricted to approximately four due to limited computer resources. Validating high-resolution outputs is not easy even when observations of AMeDAS are used, which is a high-density station data network at a spatial interval of approximately $20 \mathrm{~km}$ over Japanese Islands maintained by the JMA. Therefore, an optimum resolution that guarantees reliability of the outputs is not so high. For users who desire high-resolution information,

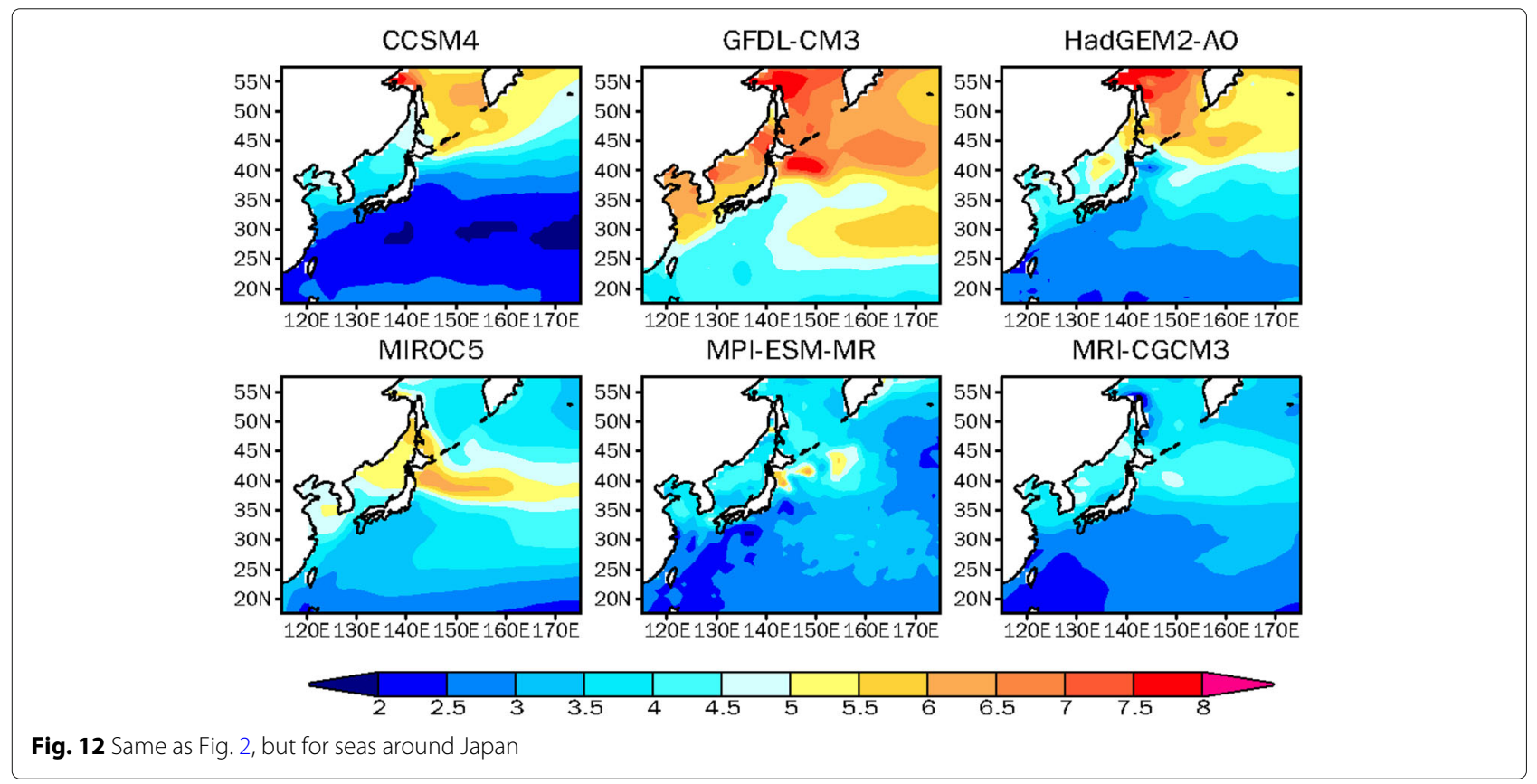


dynamical downscaling to higher resolution is one of the solutions (Hoshino et al. 2020; Kawase et al. 2018; Kawase et al. 2020; Sasai et al. 2019). Meanwhile, the models used in d4PDF are the same as those used operationally at JMA. Thus, the model performances are verified every day on an operational basis. The current resolution of the JMA operational regional model is a $2 \mathrm{~km}$ mesh, which is expected to reach $1 \mathrm{~km}$ or less in the future. At present, only products of temperature and precipitation are satisfactory to users. Other products such as relative humidity, wind, and solar radiation also have user applications. To improve performance on climatological time scales, detailed land processes and an urban model have been introduced to the current model (Murata et al. 2013). It is inevitable that the regional model becomes an earth system model, including the human components (Giorgi 2019).

\section{Abbreviations \\ AGCM: Atmospheric General Circulation Model; AMeDAS: Automated Meteorological Data Acquisition System; CMIP5: Climate Model Intercomparison Project Phase 5; d4PDF: Database for policy decision-making for future climate changes; DIAS: Data Integration and Analysis System; IPCC: Intergovernmental Panel on Climate Change; JAMSTEC: Japan Agency for Marine-Earth Science and Technology; JMA: Japan Meteorological Agency MEXT: Ministry of Education, Culture, Sports, Science, and Technology, Japan; MRI: Meteorological Research Institute; NIES: National Institute for Environmental Studies; RCP8.5: Representative Concentration Pathway with a radiative forcing level of $8.5 \mathrm{~W} / \mathrm{m}^{2}$; SI-CAT: Social Implementation Program on Climate Change Adaptation Technology}

\section{Acknowledgements}

The Earth Simulator (ES) maintained by JAMSTEC is extremely useful for conducting the large-ensemble climate simulations, and the continuous supports of the ES staff members on our global warming studies are thankfully acknowledged. Their appreciation is extended to Prof. Kimoto, Prof. Nakakita, Dr. Takayabu, all colleagues of the d4PDF team, and DIAS staff members who worked together for planning, model integration, post processing, writing papers, and data management. Figures and processed data were provided by Drs. Y. Imada, R. Mizuta, Y. Okada, Y. Tachikawa, T. Tanaka, and K. Yoshida.

\section{Authors' contributions}

MI designed the review. Topics on climate studies were summarized by MI and others on risk assessment and social implementations by NM. All authors read and approved the final manuscript.

\section{Authors' information}

MI and NM have participated respectively in Theme C: Integrated Climate Change Projection and Theme D: Integrated Hazard Prediction of Integrated Research Program for Advancing Climate Models (TOUGOU).

\section{Funding}

This work was supported by Program for Risk Information on Climate Change (SOUSEl, from FY2012 to FY2016) program, Integrated Research Program for Advancing Climate Models (TOUGOU, from FY2017 to FY2021; Grant Numbers: JPMXD0717935561, JPMXD0717935498), Social Implementation Program on Climate Change Adaptation Technology (SI-CAT, from FY2015 to FY2019), and Data Integration and Analysis System (DIAS) funded by the Ministry of Education, Culture, Sport, Science, and Technology (MEXT), Japan. The Earth Simulator was used for building up the database under "Strategic Project with Special Support" (FY2015) of JMASTEC.

\section{Availability of data and materials}

The general information is available at http://www.miroc-gcm.jp/ pub/ d4PDF/index_en.html except for simulations recently performed. All data of d4PDF are downloadable from the DIAS repository. The entries of the global and regional model outputs are http://search.diasjp.net/en/dataset/d4PDF_ GCM and http://search.diasjp.net/en/dataset/d4PDF_RCM, respectively. The database is open to any users in domestic and foreign countries, regardless uses for profit or non-profit purposes since 20 August 2018.

\section{Competing interests}

The authors declare that they have no competing interest.

\section{Author details}

'Department of Atmosphere, Ocean and Earth System Modeling Research, Meteorological Research Institute, 1-1 Nagamine, Tsukuba, Ibaraki 305-0052, Japan. ${ }^{2}$ Climate and Environment Research Promotion, Japan Meteorological Business Support Center, Kanda-Nishikicho, Chiyoda-ku, Tokyo 101-0054, Japan. ${ }^{3}$ Disaster Prevention Research Institute, Kyoto University, Gokasho, Uji, Kyoto 611-0011, Japan.

Received: 24 December 2019 Accepted: 31 August 2020

Published online: 07 October 2020

\section{References}

Adachi Y, Yukimoto S, Deushi M, Obata A, Nakano H, Tanaka TY, Hosaka M, Sakami T, Yoshimura H, Hirabara M, Shindo E, Tsujino H, Mizuta R, Yabu S, Koshiro T, Ose T, Kitoh A (2013) Basic performance of a new earth system model of the Meteorological Research Institute (MRI-ESM1). Pap Meteor Geophys 64:1-19. https://doi.org/10.2467/mripapers.64.1

Adler RF, Huffman GJ, Chang A, Ferraro R, Xie P-P, Janowiak J, Rudolf B, Schneider U, Curtis S, Bolvin D, et al (2003) The version-2 global precipitation climatology project (GPCP) monthly precipitation analysis (1979-present). J Hydrometeorol 4(6):1147-1167

Al Mohit MA, Yamashiro M, Hashimoto N, Mia M, Ide Y, Kodama M (2018) Impact assessment of a major river basin in Bangladesh on storm surge simulation. J Mar Sci Eng 6(3):99. https://doi.org/10.3390/JMSE6030099

Bourke RH, Garrett RP (1987) Sea ice thickness distribution in the Arctic Ocean. Cold Reg Sci Technol 13:259-280

Collins W, Bellouin N, Doutriaux-Boucher M, Gedney N, Halloran P, Hinton T, Hughes J, Jones C, Joshi M, Liddicoat S, et al (2011) Development and evaluation of an Earth-System model-HadGEM2. Geosci Model Dev 4(2):997-1062

Delworth TL, Broccoli AJ, Rosati A, Stouffer RJ, Balaji V, Beesley JA, Cooke WF, Dixon KW, Dunne J, Dunne K, et al (2006) GFDL's CM2 global coupled climate models. Part I: formulation and simulation characteristics. J Clim 19(5):643-674

Donner L, Wyman BL, Hemler RS, Horowitz LW, Ming Y, Zhao M, Golaz J-C, Ginoux P, Lin S-J, Schwarzkopf MD, et al (2011) The dynamical core, physical parameterizations, and basic simulation characteristics of the atmospheric component AM3 of the GFDL global coupled model CM3. J Clim 24(13):3484-3519

Duan A, Sui C, Wu G (2008) Simulation of local air-sea interaction in the great warm pool and its influence on Asian monsoon. J Geophys Res 113(D22). https://doi.org/10.1029/2008JD010520

Duan W, Hanasaki N, Shiogama H, Chen Y, Zou S, Nover D, Zhou B, Wang Y (2019) Evaluation and future projection of Chinese precipitation extremes using large ensemble high-resolution climate simulations. J Clim 32(8):2169-2183

Endo H, Kitoh A, Mizuta R, Ishii M (2017) Future changes in precipitation extremes in East Asia and their uncertainty based on large ensemble simulations with a high-resolution AGCM. SOLA 13:7-12

Fujita M, Mizuta R, Ishii M, Endo H, Sato T, Okada Y, Kawazoe S, Sugimoto S, Ishihara K, Watanabe S (2019) Precipitation changes in a climate with 2-K surface warming from large ensemble simulations using 60-km global and 20-km regional atmospheric models. Geophys Res Lett 46(1):435-442

Gent PR, Danabasoglu G, Donner LJ, Holland MM, Hunke EC, Jayne SR, Lawrence DM, Neale RB, Rasch PJ, Vertenstein M, et al (2011) The community climate system model version 4. J Clim 24(19):4973-4991

Giorgi F, Jones C, Asrar GR, et al (2009) Addressing climate information needs at the regional level: the CORDEX framework. World Meteorol Organ (WMO) Bull 58(3):175

Giorgetta MA, Jungclaus J, Reick CH, Legutke S, Bader J, Böttinger M, Brovkin V, Crueger T, Esch M, Fieg K, et al (2013) Climate and carbon cycle changes from 1850 to 2100 in MPI-ESM simulations for the Coupled Model Intercomparison Project phase 5. J Adv Model Earth Syst 5(3):572-597 
Giorgi F (2019) Thirty years of regional climate modeling: where are we and where are we going next? J Geophys Res Atmos 124(1 1):5696-5723

Hajima T, Watanabe M, Yamamoto A, Tatebe H, Noguchi MA, Abe M, Ohgaito R, Ito A, Yamazaki D, Okajima H, et al (2020) Development of the MIROC-ES2L Earth system model and the evaluation of biogeochemical processes and feedbacks. Geosci Model Dev 13:2197-2244

Hanittinan P, Tachikawa Y, Ichikawa Y, Yorozu K (2018) Future river discharge projections at the Indochinese Peninsula using large ensemble climate dataset. J Jpn Soc Civ Eng, Ser B1 Hydraul Eng 74(4):193-198

Harada M, Maruya Y, Kojima T, Matsuoka D, Nakagawa Y, Kawahara S, Araki F (2018) Flood frequency analysis and impact assessment for climate change in the Nagara river basin. J Jpn Soc Civ Eng, Ser B1 Hydraul Eng 74:181-186. (in Japanese)

Hasumi H, Emori S (2004) K-1 coupled GCM (MIROC) description. K-1 Tech. Rep. 1, Center for Climate System Research, University of Tokyo. National Institute for Environmental Studies, Frontier Research Center from Global Change: $34 \mathrm{pp}$

Hatsuzuka D, Sato T (2019) Future changes in monthly extreme precipitation in Japan using large-ensemble regional climate simulations. J Hydrometeorol 20(3):563-574. https://doi.org/10.1175/JHM-D-18-0095.1

Hatsuzuka D, Sato T, Yoshida K, Ishii M, Mizuta R (2020) Regional projection of tropical-cyclone-induced extreme precipitation around Japan based on large ensemble simulations. Sola 16:23-29

Herring SC, Christidis N, Hoell A, Hoerling MP, Stott PA (2019) Explaining extreme events of 2017 from a climate perspective. Americal Meteorological Society, Boston, USA. https://doi.org/10.1175/BAMSExplaining ExtremeEvents2017.1

Hibino K, Takayabu I (2016) A trade-off relation between temporal and spatial averaging scales on future precipitation assessment. J Meteor Soc Jpn 94:121-134. https://doi.org/10.2151/jmsj.2015-056

Hirahara S, Ishii M, Fukuda Y (2014) Centennial-scale sea surface temperature analysis and its uncertainty. J Clim 32(16):57-75. https://doi.org/10.1175/ JCLI-D-12-00837.1

Hori ME, Oshima K (2018) Robustness of the Warm Arctic/Cold Eurasian signature within a large ensemble model experiment. SOLA 14:69-73. https://doi.org/10.2151/sola.2018-012

Hoshino T, Yamada TJ (2018a) Analysis of spatiotemporal characteristics of annual maximum rainfall using a large-ensemble dataset (d4PDF): application to Tokachi river basin. J Jpn Soc Civ Eng Ser G Environ Res 74:I_25-I_31.https://doi.org/10.2208/jscejer.74.I_25 (in Japanese)

Hoshino T, Yamada T (2018b) Analysis of annual maximum precipitation over first-class river domains in Japan using a large-ensemble dataset (d4PDF). J Jpn Soc Civ Eng, Ser B1 Hydraul Eng 74:I_187-I_192. https://doi.org/10. 2208/jscejhe.74.I_187 (in Japanese)

Hoshino T, Yamada TJ, Kawase H (2020) Evaluation for characteristics of tropical cyclone induced heavy rainfall over the sub-basins in the central Hokkaido, northern Japan by 5-km large ensemble experiments. Atmosphere 11(5):435

Ide Y, Nakao N, Kodama M, Hashimoto N, Yamashiro M (2018) Study on differences in typhoon characteristics due to sea surface temperature patterns under near-future climate. J Jpn Soc Civ Eng Ser B3 Ocean Eng 74:587-592. https://doi.org/10.2208/jscejoe.74.I_587 (in Japanese)

lizumi T, Shiogama H, Imada Y, Hanasaki N, Takikawa H, Nishimori M (2018a) Crop production losses associated with anthropogenic climate change for 1981-2010 compared with preindustrial levels. Int J Climatol 38(14):5405-5417

lizumi T, Masutomi Y, Takimoto T, Hirota T, Yatagai A, Tatsumi K, Kobayashi K, Hasegawa T (2018b) Emerging research topics in agricultural meteorology and assessment of climate change adaptation. J Agric Meteorol 74(1):54-59

Imada Y, Maeda S, Watanabe M, Shiogama H, Mizuta R, Ishii M, Kimoto M (2017) Recent enhanced seasonal temperature contrast in Japan from large ensemble high-resolution climate simulations. Atmosphere 8(3):57 https://doi.org/10.3390/atmos8030057

Imada Y, Watanabe M, Kawase H, Shiogama H, Arai M (2019) The July 2018 high temperature event in Japan could not have happened without human-induced global warming. SOLA:15-002. https://doi.org/10.2151/ sola.15A-002

Jenkins GJ, Murphy JM, Sexton DMH, Lowe JA, Jones P, Kilsby CG (2009) UK Climate Projections: briefing report. http://cedadocs.ceda.ac.uk/1321/

Kamae Y, Shiogama H, Imada Y, Mori M, Arakawa O, Mizuta R, Yoshida K, Takahashi C, Arai M, Ishii M, et al (2017a) Forced response and internal variability of summer climate over western North America. Clim Dyn 49:403-417

Kamae Y, Mei W, Xie S-P, Naoi M, Ueda H (2017b) Atmospheric rivers over the Northwestern Pacific: climatology and interannual variability. J Clim 30(15):5605-5619

Kamae Y, Mei W, Xie S-P (2019) Ocean warming pattern effects on future changes in East Asian atmospheric rivers. Environ Res Lett 14(5):054019. https://doi.org/10.1088/1748-9326/ab128a

Kanada S, Tsuboki K, Takayabu I (2020) Future changes of tropical cyclones in the midlatitudes in 4-km-mesh downscaling experiments from large-ensemble simulations. SOLA 16:57-63. https://doi.org/10.2151/sola. 2020-010

Kawamiya M, Yoshikawa C, Kato T, Sato H, Sudo K, Watanabe S, Matsuno T (2005) Development of an integrated earth system model on the Earth Simulator. J Earth Simul 4:18-30

Kawase H, Murata A, Mizuta R, Sasaki H, Nosaka M, Ishii M, Takayabu I (2016) Enhancement of heavy daily snowfall in central Japan due to global warming as projected by large ensemble of regional climate simulations. Clim Chang 139(2):265-278. https://doi.org/10.1007/s10584-016-1781-3

Kawase H, Sasai T, Yamazaki T, Ito R, Dairaku K, Sugimoto S, Sasaki H, Murata A, Nosaka M (2018) Characteristics of synoptic conditions for heavy snowfall in western to northeastern Japan analyzed by the 5-km regional climate ensemble experiments. J Meteorol Soc Jpn Ser II 96(2):161-178. https:// doi.org/10.2151/jmsj.2018-022

Kawase H, Imada Y, Sasaki H, Nakaegawa T, Murata A, Nosaka M, Takayabu I (2019) Contribution of historical global warming to local-scale heavy precipitation in western Japan estimated by large ensemble high-resolution simulations. J Geophys Res Atmos 124(12):6093-6103

Kawase H, Yamazaki T, Sugimoto S, Sasai T, Ito R, Hamada T, Kuribayashi M, Fujita M, Murata A, Nosaka M, et al (2020) Changes in extremely heavy and light snow-cover winters due to global warming over high mountainous areas in central Japan. Prog Earth Planet Sci 7:10. https://doi.org/10.1186/ s40645-020-0322-x

Kim S, Tachikawa Y, Nakakita E (2017) Statistical downscaling of AGCM60km precipitation based on spatial correlation of AGCM20km output. Hydrol Res Lett 11(1):58-64

Kim K-M, Ito S, Yoshida S, Sadohara S (2018) Analysis of influence of climate change on demand and system of heating and cooling predicted by d4PDF: a case of Minatomirai 21 DHC Area in Yokohama. J Environ Eng Trans AlJ 84:83-91

Kimura N, Kiri H, Kitagawa I (2018) The impact of multiple typhoons on severe floods in the mid-latitude region (Hokkaido). Water 10(7):843

Kitoh A, Ose T, Takayabu I (2016) Dynamical downscaling for climate projection with high-resolution MRI AGCM-RCM. J Meteorol Soc Jpn Ser II 94:1-16. https://doi.org/10.2151/jmsj.2015-022

Kitano T, Takahashi R, Tanaka S (2017) Comprehensible estimation of return levels of extreme precipitation in utilizing numerous ensemble members produced by climate model. J Jpn Soc Civ Eng Ser B1 Hydraul Eng 73:1-6. https://doi.org/10.2208/jscejhe.73.I_1 (in Japanese)

Kitoh A, Endo H (2019) Future changes in precipitation extremes associated with tropical cyclones projected by large-ensemble simulations. J Meteorol Soc Jpn Ser II 97(1):141-152. https://doi.org/10.2151/jmsj.2019-007

Knapp KR, Kruk MC, Levinson DH, Diamond HJ, Neumann CJ (2010) The international best track archive for climate stewardship (IBTrACS) unifying tropical cyclone data. Bull Am Meteorol Soc 91(3):363-376

Knutson TR, Sirutis JJ, Zhao M, Tuleya RE, Bender M, Vecchi GA, Villarini G, Chavas D (2015) Global projections of intense tropical cyclone activity for the late twenty-first century from dynamical downscaling of CMIP5/RCP4. 5 scenarios. J Clim 28(18):7203-7224

Kobayashi C, Maeda S, Ito A, Matsushita Y, Takano K (2005) Relation between SSTs and predictability of seasonal mean precipitation over the western tropical Pacific. J Meteorol Soc Jpn Ser II 83(5):919-929

Kojima T, Maruyama Y, Harada M (2018) Proposal of the correction formula of probability rainfall produced by 20-km d4pdf for Gifu Prefecture. J Jpn Soc Civ Eng Ser B1 Hydraul Eng 74:133-138. https://doi.org/10.2208/jscejhe.74. 5_I_13 (in Japanese)

Kossin JP (2018) A global slowdown of tropical-cyclone translation speed. Nature 558(7708):104-107

Kuzuha Y, Senda M (2018) Consideration on nonstationarity and extreme value of precipitation by using AMeDAS and d4PDF data. J Jpn Soc Civ Eng Ser B1 Hydraul Eng 74:325-330. https://doi.org/10.2208/jscejhe.74.I_325 (in Japanese) 
Leduc M, Mailhot A, Frigon A, Martel J-L, Ludwig R, Brietzke GB, Giguère M, Brissette F, Turcotte R, Braun M, et al (2019) The ClimEx project: a 50-member ensemble of climate change projections at 12-km resolution over Europe and northeastern North America with the Canadian Regional Climate Model (CRCM5). J Appl Meteorol Climatol 58(4):663-693. https:// doi.org/10.1175/JAMC-D-18-0021.1

Maher N, Milinski S, Suarez-Gutierrez L, Botzet M, Kornblueh L, Takano Y, Kröger J, Ghosh R, Hedemann C, Li C, et al (2019) The Max Planck Institute grand ensemble-enabling the exploration of climate system variability. J Adv Model Earth Syst 11:2050-2069. https://doi.org/10.1029/2019MS001639

Martin G, Bellouin N, Collins W, Culverwell I, Halloran P, Hardiman S, Hinton T, Jones C, McDonald R, McLaren A, et al (2011) The HadGEM2 family of met office unified model climate configurations. Geosci Model Dev 4(3):723-757

Masuya S, Uemura F, Yoshida T, Oomura N, Chiba M, Tomura S, Yamamoto T, Tokioka S, Sasaki H, Hamada Y, et al (2018) Probability rainfall considering uncertainty based on a massive ensemble climate projections in actual river basin. J Jpn Soc Civ Eng Ser B1 Hydraul Eng 74(5):121-126. (in Japanese)

Matsueda M, Endo H (2017) The robustness of future changes in Northern Hemisphere blocking: a large ensemble projection with multiple sea surface temperature patterns. Geophys Res Lett 44(10):5158-5166. https:// doi.org/10.1002/2017GL073336

Matsuoka D, Sugimoto S, Nakagawa Y, Kawahara S, Araki F, Onoue Y, liyama M, Koyamada K (2019) Automatic detection of stationary fronts around Japan using a deep convolutional neural network. SOLA 15:154-159. https://doi. org/10.2151/sola.2019-028

Mei W, Kamae Y, Xie S-P, Yoshida K (2019) Variability and predictability of North Atlantic hurricane frequency in a large ensemble of high-resolution atmospheric simulations. J Clim 32(11):3153-3167. https://doi.org/10 1175/JCLI-D-18-0554.1

MetOffice (2018) UKCP18 science overview executive summary. https://www. metoffice.gov.uk/research/approach/collaboration/ukcp/

Ministry of the Environment (2018) Climate change adaptation law. http:// www.env.go.jp/earth/tekiou.html (in Japanese)

Mizuta R, Yoshimura H, Murakami H, Matsueda M, Endo H, Ose T, Kamiguchi K, Hosaka M, Sugi M, Yukimoto S, et al (2012) Climate simulations using MRI-AGCM3.2 with 20-km grid. J Meteorol Soc Jpn Ser II 90:233-258. https://doi.org/10.2151/jmsj.2012-A12

Mizuta R, Murata A, Ishii M, Shiogama H, Hibino K, Mori N, Arakawa O, Imada Y, Yoshida K, Aoyagi T, et al (2017) Over 5,000 years of ensemble future climate simulations by $60-\mathrm{km}$ global and 20-km regional atmospheric models. Bull Am Meteorol Soc 98(7):1383-1398. https://doi.org/10.1175/ BAMS-D-16-0099.1

MLIT (2019) Technical review meeting on flood control plan based on climate change. https://www.mlit.go.jp/river/shinngikai_blog/chisui_kentoukai/ (in Japanese)

MLIT (2020) Social capital development council. https://www.mlit.go.jp/river/ shinngikai_blog/shaseishin/kasenbunkakai/shouiinkai/kikouhendou_ suigai/ (in Japanese)

MLIT and MAFF (2020) Technical review meeting for coastal conservation based on climate change. https://www.mlit.go.jp/river/shinngikai_blog/ hozen/ (in Japanese)

Mori M, Watanabe M, Shiogama H, Inoue J, Kimoto M (2014) Robust Arctic sea-ice Please provide the access dates for references [MetOffice (2018), Ministry of the Environment (2018), MLIT (2019), MLIT (2020), MLIT and MAFF (2020), and Osaka Prefecture (2020)].influence on the frequent Eurasian cold winters in past decades. Nat Geosci 7(12):869

Mori N, Kjerland M, Nakajo S, Shibutani Y, Shimura T (2016) Impact assessment of climate change on coastal hazards in Japan. Hydrol Res Lett 10(3):101-105

Mori N, Takemi T (2016) Impact assessment of coastal hazards due to future changes of tropical cyclones in the North Pacific Ocean. Weather Clim Extremes 11:53-69

Mori N, Shimura T, Yoshida K, Mizuta R, Okada Y, Fujita M, Khujanazarov T, Nakakita E (2019) Future changes in extreme storm surges based on mega-ensemble projection using $60-\mathrm{km}$ resolution atmospheric global circulation model. Coast Eng J 61 (3):295-307

Morim J, Hemer M, Wang XL, Cartwright N, Trenham C, Semedo A, Young I, Bricheno L, Camus P, Casas-Prat M, et al (2019) Robustness and uncertainties in global multivariate wind-wave climate projections. Nat Clim Chang 9(9):711-718
Murakami H, Mizuta R, Shindo E (2012) Future changes in tropical cyclone activity projected by multi-physics and multi-SST ensemble experiments using the 60-km-mesh MRI-AGCM. Clim Dyn 39:2569-2584

Murata A, Sasaki H, Hanafusa M, Kurihara K (2013) Estimation of urban heat island intensity using biases in surface air temperature simulated by a nonhydrostatic regional climate model. Theor Appl Climatol 112:351-361. https://doi.org/10.1007/s00704-012-0739-2

Murata A, Sasaki H, Kawase H, Nosaka M, Aoyagi T, Oh'izumi M, Seino N, Shido F, Hibino K, Ishihara K, et al (2017) Projection of future climate change over Japan in ensemble simulations using a convection-permitting regional climate model with urban canopy. SOLA 13:219-223

Nagata M, Ikawa M, Yoshizumi S, Yoshida T (1986) On the formation of a convergent cloud band over the Japan Sea in winter; numerical experiments. J Meteorol Soc Jpn Ser II 64(6):841-855

Nakakita E, Osakada Y (2018) Estimation of future changes in the heavy rainfall and atmospheric characteristics in Baiu season under climate change. J Jpn Soc Civ Eng Ser B1 Hydraul Eng 74:139-144. https://doi.org/10.2208/ jscejhe.74.I_139 (in Japanese)

Nakakita E, Tachikawa Y, Takemi T, Mori N, Tanaka K (2018) Future changes of extreme weather and natural disasters due to climate change in Japan and Southeast Asia. In: Jung H-S, Wang B (eds). Bridging Sci Policy Implication Manag Climate Extremes. pp 101-117. https://doi.org/10.1142/ 9789813235663_0007

Nakagawa Y, Onoue Y, Kawahara S, Araki F, Koyamada K, Matsuoka D, Ishikawa Y, Fujita M, Sugimoto S, Okada Y, et al (2020) Development of a system for efficient content-based retrieval to analyze large volumes of climate data. Prog Earth Planet Sci 7(1):1-10

Noda A, Tokioka T (1989) The effect of doubling the CO2 concentration on convective and non-convective precipitation in a general circulation model coupled with a simple mixed layer ocean model. J Meteorol Soc Jpn Ser II 67(6):1057-1069

Nosaka M, Ishii M, Shiogama H, Mizuta R, Murata A, Kawase H, Sasaki H (2020) Scalability of future climate changes for $+1.5 \mathrm{~K},+2 \mathrm{~K}$, and $+4 \mathrm{~K}$ global warming in NHRCM large ensemble simulations. Progr Earth Planet Sci 7:27. https://doi.org/10.1186/s40645-020-00341-3

Nozawa T, Nagashima T, Ogura T, Yokohata T, Okada N, Shiogama H (2007) Climate change simulations with a coupled oceanatmosphere GCM called the model for interdisciplinary research on climate: MIROC. CGER Supercomput Monogr Rep: 80pp 12

Ogata T, Mizuta R, Adachi Y, Murakami H, Ose T (2016) Atmosphere-ocean coupling effect on intense tropical cyclone distribution and its future change with 60 km-AOGCM. Sci Rep 6:29800. https://doi.org/10.1038/ srep29800

Ohba M, Sugimoto S (2019) Differences in climate change impacts between weather patterns: possible effects on spatial heterogeneous changes in future extreme rainfall. Clim Dyn 52:4177-4191. https://doi.org/10.1007/ s00382-018-4374-1

Ohba M, Kawase H (2020) Rain-on-snow events in Japan as projected by a large ensemble of regional climate simulations. Clim Dyn. (accepted) https://doi.org/10.1007/s00382-020-05419-8

Ohba M, Sugimoto S (2020) Impacts of climate change on heavy wet snowfall in Japan. Clim Dyn 54(5):3151-3164

Osakada Y, Nakakita E (2018a) Future change of occurrence frequency of Baiu heavy rainfall and its linked atmospheric patterns by multiscale analysis. SOLA 14:79-85. https://doi.org/10.2151/sola.2018-014

Osakada Y, Nakakita E (2018b) Baiu heavy rainfall duration and accumulated precipitation using the regional climate model verified with past real heavy rainfall events. J Jpn Soc Civ Eng Ser B1 Hydraul Eng 74(5):19-24. (in Japanese)

Osaka Prefecture (2020) Osaka prefectural council for river structures. http:// www.pref.osaka.lg.jp/kasenkankyo/kasenkouzoubutu/ (in Japanese)

Pörtner H-O, Roberts DC, Masson-Delmotte V, Zhai P, Tignor M, Poloczanska E, Mintenbeck K, Alegrîa A, Nicolai M, Okem A, Petzold J, Rama B, Weyer NM (2019) IPCC special report on the ocean and cryosphere in a changing climate. Cambridge University Press, Cambridge, UK

Rayner NA, Parker DE, Horton EB, Folland CK, Alexander LV, Rowell DP, Kent EC, Kaplan A (2003) Global analyses of sea surface temperature, sea ice, and night marine air temperature since the late nineteenth century. J Geophys Res 108:14-44071010292002002670

Rowell DP, Folland CK, Maskell K, Ward MN (1995) Variability of summer rainfall over tropical North Africa (1906-92): observations and modelling. Q J R Meteorol Soc 121(523):669-704 
Sakamoto T, Komuro Y, Nishimura T, Ishii M, Tatebe H, Shiogama H, Hasegawa A, Toyoda T, Mori M, Suzuki T, et al (2012) MIROC4h - new high-resolution atmosphere-ocean coupled general circulation model. J Meteorol Soc Jpn Ser II 90(3):325-359. https://doi.org/10.2151/jmsj.2012-301

Sasaki H, Murata A, Hanafusa M, Oh'izumi M, Kurihara K (2011) Reproducibility of present climate in a non-hydrostatic regional climate model nested within an atmosphere general circulation model. SOLA 7:173-176. https:// doi.org/10.2151/sola.2011-044

Sasai T, Kawase H, Kanno Y, Yamaguchi J, Sugimoto S, Yamazaki T, Sasaki H, Fujita M, Iwasaki T (2019) Future projection of extreme heavy snowfall events with a 5-km large ensemble regional climate simulation. J Geophys Res Atmos 124(24):13975-13990

Sato T, Nakamura T (2019) Intensification of hot Eurasian summers by climate change and land-atmosphere interactions. Sci Rep 9(1):1-8. https://doi. org/10.1038/s41598-019-47291-5

Shiogama H, Hanasaki N, Masutomi Y, Nagashima T, Ogura T, Takahashi K, Hijioka Y, Takemura T, Nozawa T, Emori S (2010) Emission scenario dependencies in climate change assessments of the hydrological cycle. Clim Chang 99:321-329. https://doi.org/10.1007/s10584-009-9765-1

Shimura T, Mori N, Mase H (2015) Future projections of extreme ocean wave climates and the relation to tropical cyclones: ensemble experiments of MRI-AGCM3. 2H. J Clim 28(24):9838-9856

Shimura T, Mori N, Hemer MA (2016) Variability and future decreases in winter wave heights in the Western North Pacific. Geophys Res Lett 43(6):2716-2722

Shiogama H, Imada Y, Mori M, Mizuta R, Stone D, Yoshida K, Arakawa O, Ikeda M, Takahashi C, Arai M, et al (2016) Attributing historical changes in probabilities of record-breaking daily temperature and precipitation extreme events. SOLA 12:225-231

Shimura T, Mori N, Hemer MA (2017) Projection of tropical cyclone-generated extreme wave climate based on CMIP5 multi-model ensemble in the Western North Pacific. Clim Dyn 49(4):1449-1462

Stocker TF, Qin D, Plattner G-K, Tignor M, Allen SK, Boschung J, Nauels A, Xia Y, Bex V, Midgley PM, et al (2013) Climate change 2013: the physical science basis, vol 1535. Cambridge University Press, Cambridge, UK

Sugi M, Kawamura R, Sato N (1997) A study of SST-forced variability and potential predictability of seasonal mean fields using the JMA global model. J Meteorol Soc Jpn Ser II 75(3):717-736

Sugi M, Murakami H, Yoshida K (2017) Projection of future changes in the frequency of intense tropical cyclones. Clim Dyn 49:619-632

Sutton RT (2019) Climate science needs to take risk assessment much more seriously. Bull Am Meteorol Soc 100(9):1637-1642. https://doi.org/10.1175/ BAMS-D-18-0280.1

Tachikawa Y, Miyawaki K, Tanaka T, Yorozu K, Kato M, Ichikawa Y, Kim S (2017) Future change analysis of extreme floods using large ensemble climate simulation data. J Jpn Soc Civ Eng Ser B1 Hydraul Eng 73:77-90. https:// doi.org/10.2208/jscejhe.73.77 (in Japanese)

Takayabu I, Hibino K (2016) The skillful time scale of climate models. J Meteor Soc Jpn 94A:191-197. https://doi.org/10.2151/jmsj.2015-038

Takemi T, Okada Y, Ito R, Ishikawa H, Nakakita E (2016) Assessing the impacts of global warming on meteorological hazards and risks in Japan: philosophy and achievements of the SOUSEI program. Hydrol Res Lett 10(4):119-125

Taka Y, Ninomiya J, Mori N (2018) Future change of winter explosive cyclone using large ensemble climate prediction data. J Jpn Soc Civ Eng Ser B1 Hydraul Eng 74:175-180. https://doi.org/10.2208/jscejhe.74.I_175 (in Japanese)

Taka Y, Ninomiya J, Mori N, Kim S-Y (2019) Future change of storm surge caused by explosive cyclone in Nemuro bay using d4PDF. J Jpn Soc Civ Eng Ser B2 Coast Eng 75:1225-1230. https://doi.org/10.2208/kaigan.75.I_ 1225 (in Japanese)

Tanaka T, Tachikawa Y, Ichikawa Y, Yorozu K (2018) Flood risk curve development with probabilistic rainfall modelling and large ensemble climate simulation data: a case study for the Yodo River basin. Hydrol Res Lett 12(4):28-33. https://doi.org/10.3178/hrl.12.28

Tatebe H, Ogura T, Nitta T, Komuro Y, Ogochi K, Takemura T, Sudo K, Sekiguchi M, Abe M, Saito F, et al (2019) Description and basic evaluation of simulated mean state, internal variability, and climate sensitivity in MIROC6. Geosci Model Dev 12:2727-2765

Taylor KE, Stouffer RJ, Meehl GA (2012) An overview of CMIP5 and the experiment design. Bull Am Meteorol Soc 93(4):485-498. https://doi.org/ 10.1175/BAMS-D-11-00094.1
Tokioka T, Noda A, Kitoh A, Nikaidou Y, Nakagawa S, Motoi T, Yukimoto S, Takata K (1995) A transient CO2 experiment with the MRI CGCM: quick report. J Meteorol Soc Jpn Ser II 73(4):817-826

Tokioka S, Ikeuchi K, Otsuka K, Uonami K, Ishi K (2018) Economical assessment of flood control measures for adaptation using ensemble climate prediction dataset. J Jpn Soc Civ Eng Ser B1 Hydraul Eng 74(5):1-6. https:// doi.org/10.2208/jscejhe.74.5_I_1 (in Japanese)

Ueda H, Miwa K, Kamae Y (2018) Seasonal modulation of tropical cyclone occurrence associated with coherent Indo-Pacific variability during decaying phase of El Niño. J Meteorol Soc Jpn Ser II 96:381-390. https:// doi.org/10.2151/jmsj.2018-044

Uemura F, Masuya S, Yoshida T, Oomura N, Chiba M, Tomura S, Yamamoto T, Tokioka S, Sasaki H, Hamada Y, et al (2018) Estimation of annual maximum rainfalls based on a massive ensemble climate predictions in actual river basin. J Jpn Soc Civ Eng Ser B1 Hydraul Eng 74(5):115-120. (in Japanese)

Umeda J, Nakajo S, Mori N (2019) Development of global stochastic tropical cyclone model by using large ensemble GCM simulation data (d4PDF). J Jpn Soc Civ Eng Ser B2 Coast Eng 75:1195-1200. (in Japanese)

Watanabe M, Suzuki T, O'ishi R, Komuro Y, Watanabe S, Emori S, Takemura T, Chikira M, Ogura T, Sekiguchi M, et al (2010) Improved climate simulation by MIROC5: mean states, variability, and climate sensitivity. J Clim 23(23):6312-6335

Watanabe S, Hajima T, Sudo K, Nagashima T, Takemura T, Okajima H, Nozawa T, Kawase H, Abe M, Yokohata T, et al (2011) MIROC-ESM: model description and basic results of CMIP5-20c3m experiments. Geosci Model Dev 4(2):1063-1128. https://doi.org/10.5194/gmd-4-845-2011

Watanabe M, Shiogama H, Imada Y, Mori M, Ishii M, Kimoto M (2013) Event attribution of the August 2010 Russian heat wave. SOLA 9:65-68

Watanabe S, Nakamura M, Utsumi N (2018) The development of bias corrected hourly precipitation dataset for AMeDAS stations based on the projections from d4PDF. J Jpn Soc Civ Eng Ser B1 Hydraul Eng 74(5):127-132. https:// doi.org/10.2208/jscejhe.74.5___127 (in Japanese)

Watanabe S, Utsumi N (2018) Classifying large ensemble database of future climate projection: a case of precipitation in Japan. J Jpn Soc Civ Eng Ser B1 Hydraul Eng 74:169-174. (in Japanese)

Watanabe S, Fujita M, Kawazoe S, Sugimoto S, Okada Y, Mizuta R, Ishii M (2019) Frequency change of clear-air turbulence over the North Pacific under $2 \mathrm{~K}$ Global Warming-Ensemble projections using a 60-km atmospheric general circulation model. J Meteorol Soc Jpn Ser II 97(3):757-771. https:// doi.org/10.2151/jmsj.2019-038

Watanabe S, Yamada M, Abe S, Hatono M (2020) A novel bias correction method for super ensemble experiments and its reproducibility of design rainfall in Japan. Hydrol Res Lett 14(3):117-122. https://doi.org/10.3178/hrl. 14.117

Webb A, Shimura T, Mori N (2019) Global tropical cyclone track detection and analysis of the d4PDF mega-ensemble projection. J Jpn Soc Civ Eng Ser B2 Coast Eng 75(2):1207-1212

World Meteorological Organization (2019) WMO Statement on the State of the Global Climate in 2019. World Meteorological Organization, Geneva, Switzerland. ISBN: 978-92-62-11248-5

Xie S-P, Peng Q, Kamae Y, Zheng X-T, Tokinaga H, Wang D (2018) Eastern Pacific ITCZ dipole and ENSO diversity. J Clim 31(11):4449-4462

Yamaguchi M, Chan JC, Moon I-J, Yoshida K, Mizuta R (2020) Global warming changes tropical cyclone translation speed. Nat Commun 11(1):1-7

Yang J-A, Kim S, Mori N, Mase H (2017) Bias correction of simulated storm surge height considering coastline complexity. Hydrol Res Lett 11(2):121-127. https://doi.org/10.2208/kaigan.73.I_223 (in Japanese; need check!)

Yang J-A, Kim S, Mori N, Mase H (2018) Assessment of long-term impact of storm surges around the Korean Peninsula based on a large ensemble of climate projections. Coast Eng 142:1-8

Yoshida K, Sugi M, Mizuta R, Murakami H, Ishii M (2017) Future changes in tropical cyclone activity in high-resolution large-ensemble simulations. Geophys Res Lett 44(19):9910-9917. https://doi.org/10.1002/ 2017GL075058

Yoshida K (2019) Personal communication. October 8, 2019

Yukimoto S, Noda A, Kitoh A, Sugi M, Kitamura Y, Hosaka M, Shibata K, Maeda S, Uchiyama T (2001) The new Meteorological Research Institute coupled GCM (MRI-CGCM2). Model climate and variability,. Pap Meteorol Geophys 51(2):47-88. https://doi.org/10.2467/mripapers.51.47

Yukimoto S, Yoshimura H, Hosaka M, Sakami T, Tsujino H, Hirabara M, Tanaka T, Deushi M, Obata A, Nakano H, et al. (2011) Meteorological research 
institute earth system model version 1 (MRI-ESM1): model description. Technical Report No. 64, 88pp Meteorological Research Institute, Japan Yukimoto S, Adachi Y, Hosaka M, Sakami T, Yoshimura H, Hirabara M, Tanaka TY, Shindo E, Tsujino H, Deushi M, et al (2012) A new global climate model of the Meteorological Research Institute: MRI-CGCM3-Model description and basic performance-. J Meteorol Soc Jpn Ser II 90:23-64

Yukimoto S, Kawai H, Koshiro T, Oshima N, Yoshida K, Urakawa S, Tsujino H, Deushi M, Tanaka T, Hosaka M, et al. (2019) The Meteorological Research Institute Earth System Model version 2.0, MRI-ESM2. 0: Description and basic evaluation of the physical component. J Meteorol Soc Jpn Ser II 97(5):931-965. https://doi.org/10.2151/jmsj.2019-051

\section{Publisher's Note}

Springer Nature remains neutral with regard to jurisdictional claims in published maps and institutional affiliations.

\section{Submit your manuscript to a SpringerOpen ${ }^{\circ}$ journal and benefit from:}

- Convenient online submission

- Rigorous peer review

- Open access: articles freely available online

- High visibility within the field

- Retaining the copyright to your article

Submit your next manuscript at $\boldsymbol{~ s p r i n g e r o p e n . c o m ~}$ 